\title{
Dividendos, juros sobre capital próprio e níveis de payout: Um estudo investigativo sobre a política de distribuição de dividendos adotada pelas empresas listadas na BM\&FBovespa
}

\section{Dividends, interest on equity and payout levels: An investigative study on the dividend distribution policy adopted by listed on the BM\&FBovespa}

Dividendos, intereses sobre capital propio y niveles de payout: Un estudio investigativo sobre la política de distribución de dividendos adoptada por las empresas listadas en la BM\&FBovespa

\section{Kécia da Silveira Galvão}

Doutora em Administração na Universidade Federal de Pernambuco

Professora do Núcleo de Gestão da UFPE - CAA

Endereço: Rodovia BR-104, Km 59, s/n - Nova Caruaru

CEP: 55002-970 - Caruaru/PE - Brasil

E-mail: keciagalvao@gmail.com

Telefone: (81) 99733.9557

\section{Joséte Florencio dos Santos}

Doutor em Administração na Universidade Federal de do Rio de Janeiro

Professor do Departamento de Administração - UFPE

Endereço: Av. dos Economistas, s/n - Cidade Universitária.

CEP: 50670-901 - Recife/PE - Brasil

E-mail: jfs@ufpe.br

Telefone: (81) 99668.7477

\section{Jevuks Matheus de Araújo}

Doutor em Economia na Universidade Federal de do Rio de Janeiro

Professor do Departamento de Economia - UFPB

Endereço: Campus I, Universidade Federal da Paraíba

Via Expressa Padre Zé, 289 - Castelo Branco III

CEP: 50670-901 - João Pessoa - PB - Brasil

E-mail: jevuks@gmail.com

Telefone: (83) 99950.9996

Artigo recebido em 28/11/2016. Revisado por pares em 24/06/2017. Reformulado em 30/11/2017. Recomendado para publicação em 15/10/2018 por Carlos Eduardo Facin Lavarda Editor-Chefe). Publicado em 19/12/2018. 


\section{Resumo}

Este estudo investigou a política de distribuição de dividendos das empresas listadas na Bolsa de Valores de São Paulo entre 2002 e 2013. Assim, procurou identificar se as empresas pagaram (ou não) dividendos; quando distribuíram, se faz por meio de dividendos e/ou Juros sobre Capital Próprio; e, os níveis de payout adotados. Os resultados mostram que a maioria adota o pagamento de $25 \%$ do lucro líquido ajustado como dividendos mínimos, possivelmente para garantir participação legal nos lucros das empresas aos administradores. Porém, quando distribuem dividendos, pagam acima deste mínimo, havendo payout incremental. Sobre a forma de distribuição, há preferência em adotar apenas os dividendos como forma de remuneração dos investidores ou tê-lo em sua composição. Também foi visto que as companhias evitam mudar a política de distribuição adotada, mantendo a forma de remuneração e o nível de payout.

Palavras-Chave: Dividendos; Política de distribuição de dividendos; Níveis de payout

\section{Abstract}

This study investigated the dividend distribution policy adopted by companies listed on the Stock Exchange of São Paulo between 2002 to 2013. Thus, it sought to identify whether companies paid (or not) dividends; when distributed, is made through dividends and / or Interest on Equity; and, the payout levels adopted. The results show that the majority adopts to pay 25\% of the adjusted net profit as minimum dividends, possibly to guarantee legal participation in company profits to managers. However, when they distribute dividends pay above the minimum, there being Incremental Payout. On the distribution form, they prefer adopt dividends as a form of investor remuneration or have been in them composition. Also seen that companies avoid changing the adopted distribution policy, maintaining the form of remuneration and the payout level.

Keywords: Dividends; Dividend distribution policy; Payout levels

\section{Resumen}

Este estudio investigó la política de distribución de dividendos de las empresas listadas en la Bolsa de Valores de São Paulo entre 2002 y 2013. Así, intentó identificar si las empresas pagaron (o no) dividendos; cuando se distribuye, se hace por medio de dividendos y / o Intereses sobre Capital Propio; y los niveles de payout adoptados. Los resultados muestran que la mayoría adopta pagar el 25\% del beneficio neto ajustado como dividendos mínimos, posiblemente para garantizar participación legal en los beneficios de las empresas a los administradores. Sin embargo, entre las empresas que distribuyen dividendos pagan por encima del mínimo, hay payout Incremental. Sobre la forma de distribución, prefieren los dividendos como forma de remuneración de los inversores. También fue visto que las empresas evitan cambiar la política de distribución adoptada, manteniendo la forma de remuneración y el nivel de desembolso.

Palabras Clave: Dividendos; Política de distribución de dividendos; Niveles de payout

\section{Introdução}

A decisão sobre a política de dividendos refere-se à prática adotada pela empresa sobre quanto, como e quando distribuir os lucros obtidos aos seus sócios ao longo do tempo. Em outras palavras, é a prática seguida pelos gestores a partir da decisão de pagar dividendos ou o tamanho e o padrão de distribuição de caixa ao longo do tempo aos acionistas (LEASE et al., 2000). Para Brealey, Myers e Allen (2008), os dividendos são o principal meio das empresas devolverem dinheiro aos seus acionistas.

Segundo Al-Malkawi, Rafferty e Pillai (2010), as questões referentes a política de dividendos tem envolvido os gestores desde o surgimento da corporação comercial moderna e, 
de maneira surpreendente, continua sendo uma das questões mais contestadas em finanças. Desde a metade do último século, o estudo da política de dividendos vem tomando a atenção de escolas financeiras pela tentativa de solucionar diversas questões relativas ao assunto e formular teorias e modelos para explicar o comportamento dos dividendos corporativos. Allen, Bernardo e Welch (2000, p.1, tradução nossa) resumem o consenso atual quando concluem: "Apesar de uma série de teorias terem sido propostas na literatura para explicar a sua presença difundida, os dividendos continuam sendo um dos enigmas mais espinhosos em finanças corporativas".

Porém, apenas em ano de 1956 tem-se o primeiro marco das discussões acadêmicas sobre a política de dividendos, John Lintner lançava as bases fundamentais do entendimento moderno da política de dividendos (BRAV et al., 2005). Lintner (1956) justifica a diferença de crescimento dos lucros e dos dividendos por uma tendência de pagamento regular de dividendos, e postula a hipótese de um payout ideal. Posteriormente, Gordon (1959) dá continuidade e discute a relevância dos dividendos para aumentar o valor da empresa. Em sequência, Miller e Modigliani (1961) introduziram a discussão da irrelevância dos dividendos para o valor da empresa em um mercado perfeito, o que influenciou os primeiros estudos sobre os motivos e consequências do pagamento dos dividendos. Esta pesquisa, desde então, têm impulsionado a investigação de imperfeições do mercado e desenvolvido diferentes paradigmas para a política de dividendos, que incluem (mas não se limitam a) a hipótese efeito tributário (ELTON; GRUBER, 1970), a hipótese do efeito clientela (MILLER; MODIGLIANI, 1961; ELTON; GRUBER, 1970), a teoria da sinalização (BATTHACARYA, 1979) e a hipótese do fluxo de caixa (EASTERBROOK, 1984).

Além dessas perspectivas de imperfeição de mercado, torna-se oportuno a estudo das normas legais que envolvem o pagamento de dividendos, pois, conforme apontaram Denis e Stepanyan (2009), a obrigatoriedade legal pode ser vista como um dos fatores que explica a propensão das empresas pagarem dividendos. Vancin e Procianoy (2014) ratificam, que como as normas legais e tributárias referentes aos dividendos mudam de país para país, essas devem ser consideradas quando se pesquisar o tema.

Sobre essas políticas, no que tange as empresas brasileiras, são encontrados critérios na legislação específica que merecem ser considerados, como o pagamento de dividendos mínimos obrigatórios (payout mínimo/legal) e o pagamento de juros sobre capital próprio, por se enquadrarem no critério de proteção ao investidor e na tributação de dividendos, respectivamente. Porém, vale salientar, que poucos foram os estudos que adotaram o payout legal como base de suas pesquisas, a exemplo fora encontrado apenas por Vancin e Procianoy (2014) e por Silva et al. (2015).

Em seu estudo, Vancin e Procianoy (2014), analisando as empresas que negociam ações na BM\&FBovespa no período de 2007 a 2012, identificaram, dentre os achados, que 64\% das empresas estudadas optaram por distribuir dividendos acima do mínimo estabelecido em seus estatutos sociais e que o nível de dividendos pagos está relacionado ao setor econômico da empresa. Por sua vez, Silva et al. (2015), analisando apenas empresas que compunham os índices amplo, setorial e de governança da BM\&FBovespa entre 2010 e 2012, observaram a preponderância no pagamento de dividendos mínimos estatutários de $25 \%$, a preferência, quanto a forma de pagamento, em adotar dividendos e não JSCP e semelhante a Vancin e Procianoy (2014) encontraram relação entre o pagamento de dividendos e o setor econômico.

Com isso, é entendido que as referidas normas legais geram uma singularidade para a política de dividendos das empresas de capital aberto que negociam ações no Brasil, fazendose necessárias adequações das teorias às especificidades. Entretanto, são poucos os estudos que tratam do assunto, os quais necessitam de maior detalhamento como ampliação do período amostral e maior aprofundamento quanto a forma de pagamento de dividendos e seus níveis de 
payout.

Dessa forma, este estudo, tem o intuito aprofundar a discussão a respeito dos dividendos legais no que tange a forma e o nível de pagamento de dividendos. Para isso foi investigado se as companhias listadas na Bolsa de Valores de São Paulo (BM\&FBovespa) no período de 2002 a 2013 pagaram, ou não, dividendos; a forma que os distribuíram, se Juros sobre Capital Próprio e/ou dividendos; os níveis de payout distribuídos, que, com base no mínimo estabelecido em seus estatutos sociais e nas normas legais, foram classificados como mínimo, reduzido ou incremental.

\section{Referencial Teórico}

\subsection{Política de Dividendos: Bases Teóricas}

Partindo-se de um contexto histórico, os gestores têm se envolvido em questões sobre remuneração dos sócios desde meados do século XVI, nesse período os capitães da vela distribuíam a remuneração obtida com os financiadores da expedição marítima (FRANKFURTER; WOOD, 1997; BAKER, 2009). Desde então, a remuneração dos sócios tem sido desdobrada em práticas diversas como distribuição de grandes quantias ou mesmo do total dos lucros e atrelada a fatores diversos como a realidade econômica, o risco do negócio, a taxação do imposto de renda, o mercado de informações assimétricas, a preferência dos investidores (FRANKFURTER; WOOD, 1997).

Na segunda metade do século XX, ocorreu o marco inicial das discussões acadêmicas a respeito dos dividendos. Em 1956, John Lintner lançou as bases fundamentais do entendimento moderno da política de dividendos com a Teoria da Relevância dos Dividendos (BRAV et al, 2005), e Miller e Modigliani (1961) introduziram a discussão da irrelevância dos dividendos para o valor da empresa sob a perspectiva de um mercado perfeito.

Em seu estudo, Lintner (1956) evidencia quatro relevantes constatações: a) os gestores são relutantes em modificar a política de dividendos devido a reações dos investidores, e apenas a alteram quando têm a segurança de que poderá ser mantida; b) em consequência da relutância em modificar a política de pagamento dos dividendos, esta não é modificada na mesma proporção da variação dos lucros contábeis, fazendo com que a série temporal seja suavizada; c) os gestores acreditam que seja mais relevante a constância histórica do pagamento monetário dos dividendos do que a magnitude do Índice de Pagamento dos Dividendos (Payout ratio); d) a política de dividendos tem uma relação com o ciclo de vida das empresas, pois companhias mais jovens e em alto grau de crescimento pagam menos dividendos do que empresas mais maduras e com menos oportunidades de crescimento.

Além dessas constatações, Lintner (1956) identificou que a política de dividendos se baseia em aspectos específicos da empresa e do mercado, sob o contexto atual e experiências anteriores sobre a variação dos juros, os ganhos relativos sobre o capital, a razão preço e ganho, o fluxo interno dos fundos, a estabilidade dos ganhos, a preferência dos acionistas quanto aos ganhos e aos dividendos, dentre outros.

Sob a perspectiva de relevância dos dividendos e se voltando à preferência do investidor, Gordon (1959) observou que o investidor preferia receber seu rendimento como dividendos do que tê-lo reinvestido pela empresa, evitando, assim, incerteza em possíveis ganhos futuros. Essa preferência é tratada como Teoria do Pássaro na mão, a "Bird in the hand". Nesse contexto, o autor reitera que a distribuição de maiores parcelas do lucro (maiores payout's) reduzem a incerteza sobre o fluxo de caixa futuro, diminuindo o custo de capital e consequentemente aumentando o valor das ações. Do contrário, uma redução do pagamento dos dividendos diminuiria o valor da empresa.

Contrapondo-se à relevância dos investimentos, Miller e Modigliani (1961) 
argumentaram que o valor da empresa não dependia da política de dividendos ou de financiamento adotados, mas, tão somente, das oportunidades de investimentos que gerariam valor de fato. Assim, para os acionistas, seria indiferente receberem os dividendos ou terem os seus rendimentos reinvestidos, já que os ganhos futuros corrigidos seriam equivalentes ao valor presente dos dividendos. Também afirmaram que, para um investidor, todas as políticas de dividendos seriam efetivamente as mesmas desde que estes pudessem criar uma carteira que correspondesse as suas preferências.

Entretanto, os pressupostos trazidos por Miller e Modigliani (1961) não são atendidos em mercados de capitais imperfeitos, que carregam violações às características por eles propostas. Esta perspectiva de imperfeições ou fricções no mercado, têm impulsionado a investigação e desenvolvido diferentes paradigmas para a política de dividendos, que incluem (mas não se limitam) a ocorrência de tributação e custos de transação diferenciados para ganhos de capital e para dividendos; preferência dos acionistas; divergência dos interesses de gestores e sócios, bem como, informações assimétricas.

Elton e Gruber (1970) afirmam que quando os dividendos são tributados a uma taxa maior do que a aplicada aos ganhos de capital, ocorrerá o efeito tributário, fazendo com que maiores dividendos reduzam a riqueza dos acionistas quando comparado ao valor das ações. Os autores citados ainda reiteram que as empresas tomarão decisão com base na preferência do investidor, o efeito clientela, quando imperfeições de mercado, como custos de transações e taxas de tributação diferenciadas de ganhos de capital e de dividendos, influenciarem a preferência de investimento e os gestores modificarem a política de dividendos da empresa em função dessa preferência.

Autores como Jensen e Meckling (1976), Easterbrook (1984) e Jensen (1986) afirmam que podem ocorrer conflitos de agência relacionados ao caixa da empresa quando há muitos recursos em seu saldo, por existir a possibilidade dos gestores os utilizarem imprudentemente, em interesse próprio, desconsiderando a maximização da riqueza dos investidores. Nesse contexto, o pagamento de dividendos reduziria os fundos disponíveis aos gestores.

Já Baskin e Miranti (1988) defendem que, em mercados com assimetria informacional, decorrente de incompletudes e imprecisões informacionais aos acionistas, os dividendos seriam uma ferramenta para os gestores transmitirem informações privadas sobre o fluxo de caixa e lucratividade da empresa, ou seja, os dividendos sinalizariam informações.

Vale ressaltar que, em relação ao ambiente de realização de tais trabalhos, no Brasil há algumas diferenças quanto as normas de distribuição de dividendos e seus aspectos tributário, que são ser levadas em consideração para este estudo. Dentre essas, podem-se citar a obrigatoriedade de determinação de pagamento mínimos de dividendos pelas empresas, a existência de duas formas de distribuição dos lucros, como dividendos e como JSCP, e a ocorrência de tributação apenas se JSCP.

Porém, poucos são os autores que observam as especificidades legais brasileiras, quando se trata a propensão em pagar ou não dividendos. Neste aspecto, dois trabalhos podem ser destacados, o de Vancin e Procianoy (2014) e Silva, et al (2015). No primeiro, utilizando uma regressão logística, os autores buscaram investigar os objetivos de se pagar dividendos por parte das empresas listadas na BM\&FBovespa, analisando os fatores que as influenciam a pagar dividendos acima do mínimo obrigatório estabelecido em lei e em estatutos sociais. Para tanto, também foi considerado um período entre 2007 a 2012 e os setores a que as empresas pertencem. Dentre os resultados encontrados estão que a maior parte das empresas analisadas adotam $25 \%$ do Lucro Líquido Ajustado (LLA) como percentual mínimo obrigatório (82,1\%), distribuem dividendos acima do mínimo estabelecido (64\%) e que há diferenças quanto a distribuição de dividendos conforme a pertença a setores econômicos. Um outro relevante achado é que as empresas analisadas tendem a manter constante seu pagamento de dividendos, 
ou seja, se no ano anterior distribuíram apenas os dividendos mínimos obrigatórios, provavelmente irão adotar esta conduta no ano corrente, o mesmo ocorre para dividendos acima do mínimo estabelecido.

Voltando-se ao estudo de Silva, et al (2015), que, adotando a técnica de escalonamento multidimensional, analisaram a política de dividendos das empresas que compõem os índices amplo, setorial e de governança da BM\&FBovespa no período de 2010 a 2012. Quanto aos resultados, a respeito da determinação dos dividendos mínimos obrigatórios nos estatutos sociais, encontraram que existe uma preferência das empresas adotarem $25 \%$ do LLA. Além disso, perceberam que companhias classificadas nos setores financeiros, de energia elétrica e de utilidades são as que se comprometem a distribuir dividendos com percentuais acima dos $25 \%$. Quanto a forma de pagamento, identificaram que as empresas preferem pagar dividendos ou concomitantemente dividendos e JSCP do que apenas JSCP e que os JSCP são mais adotados por empresas que pagam payout acima de $25 \%$.

Tendo conhecimento dos resultados de estudos anteriores, para melhor compreensão das especificidades legais dos dividendos mínimos obrigatórios e das formas de distribuição destes passa-se a discussão do tratamento legal dos dividendos e dos JSCP no Brasil.

\subsection{Tratamento legal dos dividendos e dos juros sobre o capital próprio no Brasil}

A Lei 6.404/76 apresenta as obrigatoriedades a respeito das empresas de capital aberto, dentre essas, o tratamento a ser dado à distribuição dos lucros aos sócios por meio dos dividendos. Nesta norma as determinações sobre os dividendos encontram-se nos artigos 201 a 205 da Seção III, Capítulo XVI, como os dados de sua origem, dividendos obrigatórios, dividendos de ações preferenciais, dividendos intermediários e pagamento de dividendos.

No artigo 201 da referida norma são determinadas as origens dos dividendos, que podem ser do lucro líquido do exercício, dos lucros acumulados, das reservas de lucros e da conta de reserva de capital, no caso das ações preferenciais.

$\mathrm{O}$ artigo 202 trata dos dividendos mínimos obrigatórios, que equivalem a um percentual do lucro líquido ajustado do período distribuído aos sócios (o que neste estudo chamamos de payout mínimo). Este percentual deve ser descrito no estatuto social da empresa, entretanto, não o sendo, as empresas devem distribuir pelo menos $50 \%$ do lucro líquido ajustado do exercício como dividendo mínimo obrigatório. Vale destacar que para empresa que omite a distribuição de dividendo mínimo obrigatório de seu estatuto social e resolva acrescentar esta regra, a distribuição mínima deverá ser de $25 \%$ do lucro líquido ajustado do exercício.

Por sua vez o Lucro Líquido Ajustado (LLA) a que se refere este artigo 202 é obtido por meio de ajustes realizados no Resultado do Exercício, mediante deduções e reversões, conforme demonstrado no Quadro 1.

Quadro 1 - Metodologia de Cálculo do LLA

$\begin{array}{ll}\text { Resultado do Exercício } \\ (-) & \text { Prejuízos Acumulados } \\ (-) & \text { Provisão para IR } \\ (-) & \text { Participações Estatutárias } \\ (=) & \text { Lucro Líquido do Exercício: } \\ (-) & \text { Reserva legal; } \\ (+/-) & \text { Reserva para contingência; } \\ (=) & \text { Lucro Líquido Ajustado }\end{array}$

Fonte: Adaptado da Lei. 6.404/76

Segundo apresentado no Quadro 1, chega-se ao Lucro Líquido Ajustado a partir do Resultado do exercício, retirando ou revertendo valores referentes a prejuízo acumulado, pagamento de Imposto de Renda, participações estatutárias, reservas legais e reserva para contingência. 
Também com caráter de dividendos, têm-se os Juros sobre o Capital Próprio (JSCP), instituído de maneira facultativa às Companhias abertas, que vigora desde $1^{\circ}$ de janeiro de 1996 , pela Lei 9.249/95, artigo $9^{\circ}$, parágrafo $7^{\circ}$, a qual possibilitou às empresas regidas pela Lei 6.404/76, deduzir essa remuneração do valor dos dividendos.

Conforme a Lei 9.249/95, os JSCP podem ser imputados ao valor dos dividendos, desde que sem prejuízo ao $\S 2^{\circ}$, do artigo 202, da Lei $\mathrm{n}^{\circ} 6.404$, de 15 de dezembro de 1976 , que versa sobre o pagamento mínimo de dividendos e sua base de cálculo, o lucro líquido ajustado do período. Vale destacar que, nos termos do inciso IV da Deliberação CVM Nº 683/12, "os juros pagos ou creditados, a título de remuneração do capital próprio, somente poderão ser imputados ao dividendo obrigatório, pelo seu valor líquido do imposto de renda na fonte".

Voltando-se mais específicamente ao tratamento contábil e fiscal, os JSCP devem ser observados sobre três circunstâncias: a) quando pagadora de JSCP; b) quando recebedoras - se pessoa jurídica isenta de imposto e pessoa física e c) quando recebedora - as demais pessoas jurídicas.

Quanto as empresas pagadoras, a estas os JSCP são considerados despesas dedutíveis do Imposto de Renda (IR) e Constribuição Social Sobre o Lucro Líquido. Para tanto, a Lei 9.249/95 determina o direito de a empresa pagadora imputá-lo ao valor dos dividendos mínimos obrigatórios, a metodologia de cálculo e os limites para que os JSCP sejam utilizados para dedução da apuração do lucro real, base de cálculo do IRPJ e CSLL, e, assim, possam gerar economia tributária à empresa que os paga.

Segundo o art. $9^{\circ}$ da lei 9.249/95, para utilizar os JSCP no cálculo do lucro real, a empresa pagadora o deve calcular sobre as contas do Patrimônio Líquido, com exceção do valor constate na conta de reserva de reavaliação de bens ou direitos da pessoa jurídica que não seja adicionado a base de cálculo do IRPJ e CSLL e limitá-lo à variação, pro-rata dia, da Taxa de Juros de Longo Prazo (TJLP). Além disso, o pagamento dos JSCP também é condicionado à $50 \%$ do lucro do período, antes da dedução dos JSCP, ou a 50\% do saldo de lucros acumulados ou a $50 \%$ da reserva de lucros. De posse dessas especificidades Lagioia, Maciel e Libonati (2008) desenvolveram um caso prático em que são avaliadas as condições de pagamento de JSCP e constataram que a utilização do JSCP para a base de cálculo do Lucro Real proporciona economia tributária para as empresas pagadoras de JSCP, sejam elas sujeitas ou não a adicional de IR.

Passando a analisar a questão tributária dos JSCP pela ótica do acionista, mesmo não devendo haver prejuízo ao $\S 2^{\circ}$, do artigo 202, da Lei $\mathrm{n}^{\circ} 6.404$, o pagamento de JSCP pode levar maior ônus ao recebedor, conforme seu enquadramento tributário. Pelo pagamento de JSCP a empresa pagadora deve calcular o Imposto de Renda Retido na Fonte (IRRF), a uma alíquota de $15 \%$. Esse valor, se pessoa jurídica isenta de impostos ou pessoa física, deve ser considerado como tributação definitiva. Porém, se pessoa jurídica tributada pelo lucro presumido, lucro ou arbitrado, o IRRF sobre juros será considerado como antecipação do imposto devido no período de apuração, além de incidir a taxa do Programa de Integração Social (PIS) e a Contribuição para o Financiamento da Seguridade Social (COFINS). Se pessoa jurídica tributada com base no lucro real, o IRRF será considerado como antecipação do imposto devido e os JSCP deverão ser registrados como receita financeira, integrando a base de cálculo para IRPJ, CSLL, PIS e COFINS. Devem ser considerados também que quando o acionista for constituído sob a forma de Fundos de Investimentos, Clubes de Investimentos, Carteiras Administradas e qualquer outra forma de investimento associativo ou coletivo, não haverá incidência de IR sobre o JSCP (COLOMBO; TERRA, 2012).

Em síntese, já que para à empresa pagadora é proporcionada economia tributária e para o beneficiário, se pessoa jurídica, pode levar a maior ônus tributário, os JSCP estão em um contexto de interesses divergentes. Sob esse conflito Colombo e Terra (2012) investigaram a 
relação entre a estrutura de propriedade de capital e a distribuição de proventos em dinheiro das empresas brasileiras de capital aberto sob a ótica conjunta da empresa e dos acionistas. Foi encontrado por eles que a estrutura de propriedade de capital afeta a propensão e o montante de JSCP pago pelas empresas; que ocorre significante aumento do montante distribuído de JSCP em relação aos dividendos quando há participação de investidores institucionais na estrutura de controle; "desvios da relação 'uma ação - um voto' estão positivamente relacionados com a distribuição de JSCP". Esses resultados sugerem que empresas brasileiras atendem a preferências dos investidores quanto à forma de pagamento de proventos, se dividendos ou JSCP.

\subsection{Níveis de payout}

Como determinado pela Lei das S.A., as empresas devem distribuir um dividendo obrigatório, mensurado como payout. Para chegar ao payout pago pelas empresas, conforme tal norma, deve-se tomar a razão do total dos dividendos distribuídos, somatório dos JSCP líquido do IRRF e do valor dos dividendos, pelo Lucro Líquido Ajustado, como segue na (1):

$$
\text { Payout Distribuído }=\frac{J S C P \text { Líquido }+ \text { Dividendos Pagos }}{L L A}
$$

Onde, o JSCP Líquido é juros sobre capital próprio distribuído descontado o valor do Imposto de Renda Retido na Fonte; os Dividendos Pagos são os dividendos distribuídos e o LLA é Lucro Líquido ajustado, conforme Quadro 1.

Por sua vez, como há um percentual de payout mínimo obrigatório determinado no estatuto social das empresas, entende-se que a análise do pagamento de dividendos deve partir deste parâmetro, frisa-se que, porém, a empresa pode distribuir dividendos acima ou abaixo do mínimo determinado. Dessa forma são considerados três níveis de payout (I) Payout Mínimo equivale ao percentual estabelecido no estatuto social; (II) Patout Incremental - percentual pago acima do estabelecido no estatuto social; (III) Payout Reduzido - quando os dividendos distribuídos estiverem abaixo do estabelecido no estatuto social.

\section{Metodologia}

Neste capítulo, são apresentados os procedimentos que foram utilizados para identificar se as companhias listadas na Bolsa de Valores de São Paulo (BM\&FBovespa) no período de 2002 a 2013 pagaram, ou não, dividendos; a forma que os distribuíram, se Juros sobre Capital Próprio e/ou dividendos; os níveis de payout distribuídos, que, com base no mínimo estabelecido em seus estatutos sociais e nas normas legais, foram classificados como mínimo, reduzido ou incremental. Inicialmente é definida a amostra em seguida, é apresentada a fonte da coleta dos dados, a definição e operacionalização das variáveis do estudo e as técnicas de análise propostas para atingir o objeto da pesquisa.

\subsection{Amostra de Pesquisa}

A população estudada equivale as 398 empresas que negociavam ações na bolsa de valores de São Paulo em dezembro de 2014. Após a retirada de empresas que não apresentavam qualquer dado das variáveis nos anos estudados ou não havia clareza das informações sobre a política de dividendos e/ou sua distribuição, foi obtida uma amostra final de 287 empresas. Com isso, foi obtida uma amostra com 2.720 observações cuja sua frequência de distribuição no decorrer dos anos analisados é apresentado na Tabela 1, onde é destacada a classificação das 
mesmas por setor econômico conforme Economática ${ }^{\circledR}$.

Tabela 1 - Distribuição das empresas por setor econômico e ano

\begin{tabular}{|c|c|c|c|c|c|c|c|c|c|c|c|c|c|}
\hline \multirow{2}{*}{ Setor Econômico } & \multicolumn{13}{|c|}{ Amostra (\%) } \\
\hline & 2002 & 2003 & 2004 & 2005 & 2006 & 2007 & 2008 & 2009 & 2010 & 2011 & 2012 & 2013 & Total \\
\hline Agro \& Pesca & - & - & 1 & 1 & 3 & 3 & 3 & 3 & 3 & 3 & 4 & 4 & 4 \\
\hline Alimentos e Bebidas & 3 & 3 & 4 & 6 & 8 & 10 & 10 & 10 & 11 & 11 & 13 & 13 & 13 \\
\hline Comércio & 9 & 10 & 10 & 10 & 12 & 12 & 13 & 14 & 17 & 17 & 17 & 17 & 17 \\
\hline Construção & 9 & 10 & 11 & 12 & 20 & 22 & 23 & 22 & 23 & 23 & 23 & 22 & 23 \\
\hline Eletroeletrônica & 3 & 3 & 3 & 4 & 5 & 5 & 6 & 7 & 7 & 7 & 7 & 7 & 7 \\
\hline Energia Elétrica & 20 & 22 & 23 & 25 & 30 & 31 & 31 & 31 & 34 & 34 & 34 & 34 & 34 \\
\hline Finanças e Seguros & 7 & 9 & 9 & 10 & 13 & 17 & 19 & 21 & 23 & 23 & 23 & 23 & 23 \\
\hline $\begin{array}{l}\text { Maquinaria } \\
\text { Industrial }\end{array}$ & 2 & 2 & 2 & 2 & 2 & 3 & 3 & 3 & 3 & 3 & 3 & 3 & 3 \\
\hline $\begin{array}{l}\text { Minerais não } \\
\text { Metálicos }\end{array}$ & 2 & 2 & 2 & 2 & 2 & 3 & 3 & 4 & 4 & 4 & 4 & 4 & 4 \\
\hline Mineração & 3 & 3 & 3 & 3 & 3 & 3 & 3 & 4 & 4 & 4 & 4 & 4 & 4 \\
\hline Papel e Celulose & 4 & 4 & 4 & 4 & 4 & 4 & 4 & 4 & 4 & 4 & 4 & 4 & 4 \\
\hline Petróleo e Gás & 4 & 4 & 4 & 4 & 5 & 5 & 5 & 6 & 7 & 7 & 7 & 7 & 7 \\
\hline Química & 4 & 4 & 4 & 4 & 5 & 6 & 8 & 8 & 8 & 8 & 8 & 8 & 8 \\
\hline $\begin{array}{l}\text { Siderurgia \& } \\
\text { Metalurgia }\end{array}$ & 14 & 15 & 15 & 16 & 16 & 15 & 17 & 17 & 17 & 17 & 17 & 16 & 17 \\
\hline Software e Dados & - & - & - & 1 & 1 & 1 & 1 & 2 & 2 & 3 & 4 & 4 & 4 \\
\hline Telecomunicações & 5 & 5 & 5 & 5 & 5 & 5 & 5 & 6 & 6 & 6 & 6 & 6 & 6 \\
\hline Têxtil & 16 & 16 & 18 & 18 & 19 & 20 & 20 & 21 & 21 & 21 & 21 & 21 & 21 \\
\hline Transporte Serviço & 3 & 4 & 5 & 6 & 8 & 8 & 9 & 9 & 9 & 9 & 10 & 10 & 10 \\
\hline Veículos e Peças & 8 & 8 & 8 & 9 & 9 & 10 & 10 & 10 & 10 & 10 & 10 & 10 & 10 \\
\hline Outros & 28 & 32 & 33 & 38 & 43 & 49 & 54 & 57 & 63 & 64 & 67 & 68 & 68 \\
\hline Total de Empresas & 144 & 156 & 164 & 180 & 213 & 232 & 247 & 259 & 276 & 278 & 286 & 285 & 287 \\
\hline
\end{tabular}

Conforme apresentado na Tabela 1, a frequência de empresas passou de 144 em 2002 para 285 em 2013, um pouco menos do que o dobro, acredita-se que o número de empresas subiu no decorrer desses anos em virtude do aumento de empresas que negociam suas ações na BM\&FBovespa. Acredita-se também que uma maior exigência de apresentação de informações por parte da CVM em decorrência da harmonização das normas contábeis obrigou as organizações a apresentarem informações mais completas no que diz respeito aos dados utilizados neste estudo, o que também colaborou para aumento da amostra.

Quanto a distribuição conforme classificação econômica, pode-se notar que o grupo que aglutina maior número de observações é o "Outros", o que se esperava, haja vista somar empresas que não se enquadram nos demais setores. Por conseguinte, em percentual de participação dos setores na amostra, destacam-se as empresas de Energia Elétrica, com 11,85\% de participação, seguida dos setores Construção, Finanças e Seguros e Têxtil com 8,01\%, $8,01 \%, 7,32 \%$ respectivamente. Os demais segmentos permearam entre $0,70 \%$ a $5,83 \%$ de participação na amostra.

\subsection{Instrumentos de Pesquisa e Formação das Variáveis}

Os dados utilizados neste estudo são secundários e coletados nas páginas eletrônicas da CVM e da BM\&F Bovespa e na base de dados Economática ${ }^{\circledR}$. Todos os dados são anuais, obedecendo ao fim do calendário civil e abrangendo o período de 2002 a 2013. Os dados foram 
coletados entre agosto de 2014 e fevereiro de 2015 e deflacionados para janeiro de 2015 com base no Índice Geral de Preços - Disponibilidade Interna (IGP-DI).

As páginas eletrônicas da CVM e da Bolsa de Valores de São Paulo foram utilizadas para acesso aos estatutos sociais e às atas de assembleia das empresas estudadas. Nos estatutos sociais das empresas são examinadas e extraídas informações referentes à política de pagamento de dividendos, o que inclui o payout mínimo e a forma de pagamento (se dividendos e/ou juros sobre capital próprio), para o período de análise foram acompanhadas as modificações referentes aos dividendos e levadas em consideração quando ocorreram.

Nas atas de assembleia geral foram investigados o lucro líquido ajustado e/ou as informações necessárias ao seu cálculo conforme a Lei $\mathrm{n}^{\circ}$ 6.404/76, e disposto no Quadro 1, apresentado anteriormente no tópico 0 . Também foram coletadas informações relevantes sobre o pagamento de dividendos, como o seu montante e a sua forma de distribuição, se dividendos ou JSCP, para cada ano e empresa analisada. Ao final do estudo, estima-se que foram analisados cerca de 4.000 documentos, entre atas de assembleia e estatutos sociais.

De posse dos dados foram formadas as variáveis utilizadas neste estudo, a descrição das mesmas e sua instrumentação das mesmas são apresentas no Quadro 2 - Conjunto de variáveis.

\begin{tabular}{|c|c|c|c|}
\hline Variável & Descrição & Instrumentação & Base Teórica \\
\hline $\boldsymbol{L} \boldsymbol{L} \boldsymbol{A}_{t}$ & $\begin{array}{l}\text { Lucro Líquido Ajustado no ano } \\
\text { t. }\end{array}$ & Ver Quadro1 & $\begin{array}{l}\text { Lei } 6.404 / 76, \\
\text { Vancin e Procianoy } \\
\text { (2014), Silva et al } \\
\text { (2015). }\end{array}$ \\
\hline Divt & $\begin{array}{l}\text { Total dividendos pagos pela } \\
\text { empresa no ano t. }\end{array}$ & $\begin{array}{l}\text { Somatório dos valores de } \\
\text { dividendos pagos no ano }\end{array}$ & $\begin{array}{l}\text { Lei } 6.404 / 76 \text {, } \\
\text { Vancin e Procianoy } \\
\text { (2014), Silva et al } \\
\text { (2015). }\end{array}$ \\
\hline$J S C P_{t}$ & $\begin{array}{l}\text { JSCP, líquido de IRRF, pagos } \\
\text { pela empresa no ano } t .\end{array}$ & $\begin{array}{l}\text { Somatório dos valores de JSCP } \\
\text { pagos no ano descontado o IRRF }\end{array}$ & $\begin{array}{l}\text { Lei } 6.404 / 76 \text {, Silva } \\
\text { et al }(2015)\end{array}$ \\
\hline Divtot $t_{t}$ & $\begin{array}{l}\text { Somatório dos dividendos e } \\
\text { JSCP pela empresa no ano t. }\end{array}$ & Dividendos + JSCP & $\begin{array}{l}\text { Lei } 6.404 / 76 \text {, } \\
\text { Vancin e Procianoy } \\
\text { (2014), Silva et al } \\
\text { (2015). }\end{array}$ \\
\hline$S D i v_{t}$ & $\begin{array}{l}\text { Variável categórica que } \\
\text { identifica as empresas que } \\
\text { remuneraram os acionistas } \\
\text { apenas na forma de dividendos } \\
\text { no ano t. }\end{array}$ & $\begin{array}{l}\text { Recebeu o valor de } 1 \text { quando a } \\
\text { empresa distribuiu } \\
\text { dividendos e } 0 \text { do contrário. }\end{array}$ & $\begin{array}{l}\text { Contribuição deste } \\
\text { estudo. }\end{array}$ \\
\hline$S J S C P_{t}$ & $\begin{array}{l}\text { Variável categórica que } \\
\text { identifica as empresas que } \\
\text { remuneraram os acionistas } \\
\text { apenas na forma de JSCP no } \\
\text { ano t. }\end{array}$ & $\begin{array}{l}\text { Recebeu o valor de } 1 \text { quando a } \\
\text { empresa distribuiu apenas JSCP e } 0 \\
\text { do contrário. }\end{array}$ & $\begin{array}{l}\text { Contribuição deste } \\
\text { estudo. }\end{array}$ \\
\hline Divi\&JSCP & $\begin{array}{l}\text { Variável categórica que } \\
\text { identifica as empresas que } \\
\text { remuneraram os acionistas na } \\
\text { forma de dividendos e de JSCP } \\
\text { no ano t. }\end{array}$ & 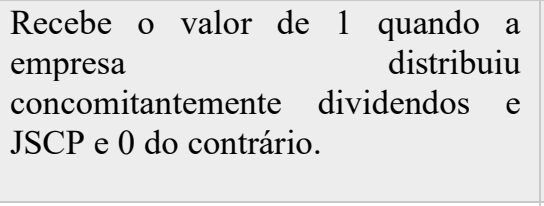 & $\begin{array}{l}\text { Contribuição deste } \\
\text { estudo. }\end{array}$ \\
\hline$D L L A_{t}$ & $\begin{array}{l}\text { Variável categórica que } \\
\text { identifica as empresas } \\
\text { obtiveram LLA positivo. }\end{array}$ & $\begin{array}{l}\text { Recebe o valor de } 1 \text { quando o } L_{L A} t \\
\text { é maior do que zero e } 0 \text { do } \\
\text { contrário. }\end{array}$ & $\begin{array}{l}\text { Contribuição deste } \\
\text { estudo }\end{array}$ \\
\hline \multirow[t]{2}{*}{ Payout $t$} & $\begin{array}{l}\text { Razão entre as variáveis Divtot } \\
\text { e LLA }\end{array}$ & $D_{t} / L L A_{t}$ & $\begin{array}{l}\text { Lei } 6.404 / 76 \text {, } \\
\text { Vancin e Procianoy } \\
\text { (2014), Silva et al } \\
\text { (2015). }\end{array}$ \\
\hline & & & Continua \\
\hline 12 & 69, UFSC, Florianól & s, v. 15, n. 36, p. 03-30, jul./set. 2018 & 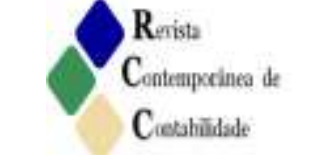 \\
\hline
\end{tabular}


Continuação

\begin{tabular}{|c|c|c|c|}
\hline Variável & Descrição & Instrumentação & Base Teórica \\
\hline Pgdiv $_{t}$ & $\begin{array}{l}\text { Variável categórica que } \\
\text { identifica as empresas que } \\
\text { pagaram dividendos }\end{array}$ & $\begin{array}{l}\text { Recebe o valor de } 1 \text {, quando a } \\
\text { empresa pagou dividendos e } 0 \text { do } \\
\text { contrário. }\end{array}$ & $\begin{array}{l}\text { Fama e French } \\
\text { (2001); DeAngelo, } \\
\text { DeAngelo, Stulz } \\
\text { (2006). }\end{array}$ \\
\hline PayoutMt & $\begin{array}{l}\text { Variável categórica que } \\
\text { identifica as empresas que } \\
\text { pagaram dividendos mínimos } \\
\text { estabelecido no estatuto social. }\end{array}$ & $\begin{array}{l}\text { Recebe o valor de } 1 \text { quando a } \\
\text { empresa pagou dividendos mínimos } \\
\text { e } 0 \text { do contrário recebe }\end{array}$ & $\begin{array}{l}\text { Contribuição deste } \\
\text { estudo }\end{array}$ \\
\hline PayoutR $_{t}$ & $\begin{array}{l}\text { Variável categórica que } \\
\text { identifica se as empresas } \\
\text { pagaram dividendos abaixo do } \\
\text { mínimo estabelecido no estatuto } \\
\text { social. }\end{array}$ & $\begin{array}{l}\text { Recebe o valor de } 1 \text { quando a } \\
\text { empresa pagou dividendos abaixo do } \\
\text { mínimo estabelecido no estatuto } \\
\text { social e } 0 \text { do contrário. }\end{array}$ & $\begin{array}{l}\text { Contribuição deste } \\
\text { estudo }\end{array}$ \\
\hline PayoutIt & $\begin{array}{l}\text { Variável categórica que } \\
\text { identifica as empresas que } \\
\text { pagaram dividendos acima do } \\
\text { mínimo estabelecido no estatuto } \\
\text { social. }\end{array}$ & $\begin{array}{l}\text { Recebe o valor de } 1 \text { quando a } \\
\text { empresa pagou dividendos acima do } \\
\text { mínimo estabelecido e } 0 \text { do } \\
\text { contrário. }\end{array}$ & $\begin{array}{l}\text { Contribuição deste } \\
\text { estudo }\end{array}$ \\
\hline $\operatorname{Acmaj}_{t}$ & $\begin{array}{l}\text { Variável categórica que } \\
\text { identifica a personificação do } \\
\text { principal acionista majoritário. }\end{array}$ & $\begin{array}{l}\text { Recebe o valor de } 1 \text { quando o } \\
\text { principal acionista majoritário é } \\
\text { pessoa jurídica e } 0 \text { quando pessoa } \\
\text { física. }\end{array}$ & $\begin{array}{l}\text { Contribuição deste } \\
\text { estudo }\end{array}$ \\
\hline
\end{tabular}

Importante salientar que o pagamento de dividendos reduzidos não indica que a empresa esteja cometendo alguma infração à legislação, pois para proteger a saúde econômica financeira e continuidade da empresa, há casos em que esta redução é permitida, o que não é discutido neste estudo.

Por sua vez, as empresas que apresentaram um LLA igual ou menor do que zero, e que por isso não tinham obrigação de distribuir dividendos no período, mas mesmo assim o fizeram, foram consideradas pagadoras de Payout Incremental. Entretanto, para evitar erros de estimação do cálculo de payout médio, estas empresas foram retiradas da amostra.

\subsection{Procedimentos de Pesquisa}

Formadas as variáveis foi investigado por meio da estatística descritiva e análise univariada, o número de empresas que realizaram pagamento de dividendos, se, para tanto, adotaram JSCP e/ou dividendos e os níveis de payout de cada ano. Vale destacar que também foram observados estes fatores em relação aos setores econômicos das empresas, conforme classificação do Economática®.

Para avaliar estatisticamente as variáveis, foram realizados testes de diferenciação de amostras, testes de correlação e a análise probabilidades de mudanças em uma variável categórica ao longo do tempo em um painel de dados.

Sobre os testes de diferenciação de amostras, foram adotados os testes não paramétricos Kruskal-Wallis e Qui-Quadrado. O primeiro foi adotado para avaliar a diferença de distribuição de três ou mais amostras e quando as variáveis são contínuas. O segundo foi usado para identificar tal diferença quando as variáveis são categóricas. Para análise de correlação, foi utilizada a correlação tetracórica, para variáveis artificialmente transformadas de contínuas para discretas e a correlação de Speraman para variáveis contínuas.

Adicionalmente, utilizando o comando xttrans, referente ao Report transition 
probabilities, do software Stata versão12, foram avaliadas as probabilidades de mudanças em uma variável categórica ao longo do tempo em um painel de dados (STATA CORPORATION, 2011). Assim, teve-se a indicação se as empresas que pagaram dividendos continuaram, ou não, a pagar dividendos ao longo dos anos e a forma como pagaram. Da mesma maneira, foi identificado se as que distribuíram payout mínimo, incremental ou reduzido, continuaram a fazê-lo durante o período avaliado.

\section{Análise dos Dados e Resultados}

Nesta seção, passa-se à análise dos dados e à discussão dos resultados com o intuito de atingir o objetivo principal deste estudo. Para tanto, esta seção é dividida em duas subseções, na primeira, discute-se a política estatutária de dividendos, evidenciando os percentuais de payout mínimo adotados pelas empresas da amostra conforme seus estatutos sociais. Posteriormente analisa-se o pagamento dos dividendos no decorrer dos anos, destacando o percentual de empresas da amostra que os distribuiu e os níveis de payout pagos pelas mesmas.

\subsection{Política Estatutária de Dividendos}

Esta seção apresenta uma discussão sobre política de dividendos, evidenciando-se o payout mínimo adotado pelas empresas deste estudo, segundo o que foi apresentado nos estatutos sociais das mesmas.

Das 287 empresas estudadas, a grande maioria (89\%) adota como payout mínimo um valor de $25 \%$ do lucro líquido ajustado. Valores de payout acima de $25 \%$ foram observados em $9 \%$ das empresas e apenas $2 \%$ da amostra adota payout menor do que $25 \%$ do LLA.

Comparando esses resultados com Vancin e Procianoy (2014), são encontrados números muito próximos, $82 \%$ das empresas por eles avaliadas apresenta $25 \%$ do LLA como dividendos mínimos obrigatórios, $5,69 \%$ se comprometem a pagar menos do que $25 \%$ e $8,1 \%$ se comprometem com um percentual maior.

Como mencionado há uma majoritariedade de distribuição de $25 \%$ do LLA, o que parece indicar uma tendência de uniformização da política de distribuição de dividendos. Para Silva et al (2015) chama a atenção que este comportamento revelam uma adequação ao "ambiente mercadológico", podendo indicar um efeito clientela. Já Vancin e Procianoy (2014) destacaram a obrigatoriedade de dividendos mínimos de $25 \%$ no caso de empresas com estatutos omissos decidirem implementar um percentual, conforme Inciso II do artigo 202 da Lei 6.404/76. Segundo os autores, este critério legal pode ter levado a uma compreensão geral de payout mínimo obrigatório de $25 \%$ por parte dos gestores. Porém, o entendimento da obrigatoriedade de qualquer percentual, com exceção ao citado caso de omissão, pode não ser a principal ou a maior motivação, principalmente nas empresas que iniciaram suas atividades após 1976, ano em que a referida lei das S.A. entrou em vigor, ou nas que existiam antes dessa data e apresentavam em seus estatutos um payout mínimo. Além disso, não é proibido às empresas modificarem o percentual de dividendos após a inclusão dos $25 \%$ como mínimo.

Uma outra justificativa, não mencionada pelos autores, e talvez a mais adequada, está no $\S 1^{\circ}$ do artigo 152 da referida Lei das S.A., em que é determinado que apenas será atribuído aos administradores participação nos lucros se, no estatuto social da empresa, o percentual for determinado como dividendos mínimos obrigatórios $25 \%$ ou mais do Lucro Líquido. Esta perspectiva indica a ocorrência de um conflito de agência por parte de administradores, que podem estar ajustando a política de distribuição de dividendos a princípio para salvaguardar os acionistas com uma remuneração mínima, mas, na verdade o está fazendo para garantir sua própria remuneração.

Voltando-se as empresas pagadoras de payout mínimo menor do que $25 \%$, vale destacar 
que todas são pertencentes ao setor de Petróleo e Gás, e adotam $0,0001 \%$ como payout mínimo.

Por sua vez, para o grupo das empresas que pagam payout acima dos $25 \%$, apresenta-se o Quadro 3, onde são apresentados os percentuais de payout propostos nos estatutos sociais, seus respectivos setores econômicos e o número de empresas.

Quadro 4 - Classificação das empresas com percentual de payout acima dos $25 \%$ do lucro líquido ajustado e por setor econômico

\begin{tabular}{|c|c|c|c|}
\hline Payout & Setor Econômico & Número de Empresas & Percentual de Empresas do Setor \\
\hline \multirow{8}{*}{$30 \%$ do LLA } & Agro \& Pesca & 1 & $25 \%$ \\
\hline & Alimentos e Bebidas & 1 & $23 \%$ \\
\hline & Energia Elétrica & 1 & $12 \%$ \\
\hline & Finanças e Seguros & 1 & $9 \%$ \\
\hline & Siderurgia e Metalurgia & 2 & $18 \%$ \\
\hline & Têxtil & 1 & $33 \%$ \\
\hline & Veículos e Peças & 1 & $20 \%$ \\
\hline & Outros & 3 & $7 \%$ \\
\hline \multirow{2}{*}{ 1/3 do LLA } & Têxtil & 4 & $33 \%$ \\
\hline & Veículos e Peças & 1 & $20 \%$ \\
\hline \multirow{2}{*}{$35 \%$ do LLA } & Siderurgia e Metalurgia & 1 & $18 \%$ \\
\hline & Têxtil & 2 & $33 \%$ \\
\hline 37\% do LLA & Outros & 1 & $7 \%$ \\
\hline $40 \%$ do LLA & Alimentos e Bebidas & 2 & $23 \%$ \\
\hline \multirow{4}{*}{$50 \%$ do LLA } & Energia Elétrica & 3 & $12 \%$ \\
\hline & Finanças e Seguros & 1 & $9 \%$ \\
\hline & Química & 1 & $13 \%$ \\
\hline & Outros & 1 & $7 \%$ \\
\hline
\end{tabular}

Conforme Quadro 4, pode-se verificar que os setores Têxtil e Outros e de Energia Elétrica são os que possuem maior número de empresas que pagam payout acima dos $25 \%, 7,5$ e 4 empresas, respectivamente.

Entretanto, se observarmos a coluna percentual, em que o número de empresas que paga payout acima dos $25 \%$ é relacionado com o número de empresas analisadas conforme setor econômico, disposto anteriormente na Tabela 1, pode-se verificar que os grupos de empresas que mais pagam dividendos acima dos $25 \%$ é o Têxtil, seguido do Agro \& Pesca e Alimentos e Bebidas e Química. Por sua vez, os setores Outros, Finanças e Seguros e Energia Elétrica são os que, das empresas que determinam os dividendos mínimos acima dos $25 \%$, tem o menor percentual de empresas.

Comparando estes achados com o de Silva et al (2015), confirma-se a propensão das empresas de Energia Elétrica e Financeiras em pagar maior payout mínimo, complementarmente tem-se novos achados em relação as empresas dos setores de Têxtil, Agro $\&$ Pesca, Alimentos e Bebidas e demais setores, que não tinham sido observados nos estudos anteriores.

\subsection{O Pagamento e a Forma de Distribuição dos Dividendos}

Nesta seção é apresentada a caracterização das empresas estudadas ao longo dos anos conforme ocorrência de distribuição de dividendos (ou não), destacando-se também o setor econômico a que pertencem. Além disso, é observada a variação dos percentuais de payout pagos no decorrer dos anos.

\subsubsection{Classificação Quanto a Distribuição de Dividendos}

Na Tabela 2, é apresentado o quantitativo das empresas que compuseram a amostra ao 
longo dos anos, identificando o percentual que distribuiu, ou não, dividendos. Com exceção de 2002 , em todos os anos do estudo, mais de $60 \%$ das empresas da amostra pagaram dividendos. Essa concentração de pagadoras pode ser relacionada à obrigatoriedade estatutária de distribuição das empresas. Também pode ser visto que, entre os anos de 2006 a 2013, o percentual de empresas não pagadoras de dividendos está entre $27 \%$ e $32 \%$, uma amplitude de cinco pontos percentuais e em 2002, tem-se o maior percentual de não pagadoras, $51 \%$.

Tabela 2 - Classificação das empresas quanto à distribuição de dividendos

\begin{tabular}{c|c|c|c|c|c|c|c|c|c|c|c|c}
\hline $\begin{array}{c}\text { Distribui } \\
\text { dividendos }\end{array}$ & $\mathbf{2 0 0 2}$ & $\mathbf{2 0 0 3}$ & $\mathbf{2 0 0 4}$ & $\mathbf{2 0 0 5}$ & $\mathbf{2 0 0 6}$ & $\mathbf{2 0 0 7}$ & $\mathbf{2 0 0 8}$ & $\mathbf{2 0 0 9}$ & $\mathbf{2 0 1 0}$ & $\mathbf{2 0 1 1}$ & $\mathbf{2 0 1 2}$ & $\mathbf{2 0 1 3}$ \\
\hline Não & $51 \%$ & $40 \%$ & $39 \%$ & $36 \%$ & $32 \%$ & $30 \%$ & $31 \%$ & $28 \%$ & $27 \%$ & $30 \%$ & $32 \%$ & $31 \%$ \\
\hline Sim & $49 \%$ & $60 \%$ & $61 \%$ & $64 \%$ & $68 \%$ & $70 \%$ & $69 \%$ & $72 \%$ & $73 \%$ & $70 \%$ & $68 \%$ & $69 \%$ \\
\hline Amostra & 144 & 156 & 164 & 180 & 213 & 232 & 247 & 259 & 276 & 278 & 286 & 285 \\
\hline
\end{tabular}

Avaliando se as empresas que pagam, ou não, dividendos continuam com essa prática ao longo dos anos, foi elaborada uma matriz de transição, apresentada na

Tabela 3, para tanto foi adotado o comando xttrans do STATA 12. Em sua interpretação combina-se a informação das linhas com a das colunas, as linhas representam o comportamento das empresas que pagaram (Pagadoras) ou não dividendos (Não Pagadoras), as Colunas representam a continuidade de distribuição (Distribuiu) ou a continuidade de não distribuição (Não Distribuiu) ao longo do período, destacando que na primeira coluna está o percentual total da amostra que não pagou dividendos e da que pagou dividendos.

Tabela 3-Continuidade de pagamento de dividendos

\begin{tabular}{|c|c|c|c|}
\hline Distribuiu dividendos & Total & Não Distribuiu & Distribuiu \\
\hline Não Pagadoras & $31,89 \%$ & $82,42 \%$ & $17,58 \%$ \\
\hline Pagadoras & $68,11 \%$ & $7,05 \%$ & $92,95 \%$ \\
\hline
\end{tabular}

Conforme indicado, na primeira coluna, indica-se, do total de observações da amostra, o percentual que não pagou dividendos $(31,89 \%)$ e o que pagou $(68,11 \%)$. No cruzamento da primeira linha com a segunda coluna (Não Pagadoras x Não Distribuiu), identifica-se que, do percentual de empresas que não pagou dividendos $(31,89 \%), 82,42 \%$ assim se mantiveram por todo o período; pela combinação da primeira linha com a terceira coluna (Pagadoras X Distribuiu) tem-se que, do percentual das empresas que não pagou dividendos $(31,89 \%)$, $17,58 \%$ passou a distribuí-los em algum momento. Voltando-se à segunda linha e combinandoa com a segunda coluna (Pagadoras x Não Distribuiu) encontra-se que, do percentual da amostra que pagou dividendo $(68,11 \%), 7,05 \%$ deixou de distribuí-los em algum ano; por fim, combinando a segunda linha com a terceira coluna (Pagadoras x Distribuiu), encontra-se que, do percentual de empresas que distribuiu dividendos $(68,11 \%), 92,95 \%$ o fez por todo o período.

Sobre esta continuidade de pagamento buscou-se investigar se o pagamento de dividendos está associado a ocorrência de LLA positivo, ou se os gestores o fazem para os porque são relutantes em modificar a política de dividendos como preconizado por Lintner (1956).

Para averiguar se o pagamento de dividendos está associado à existência de LLA positivo, foi investigada a intensidade da relação entre as variáveis categóricas $\boldsymbol{D L L A t}$ e Pgdiv, que identificam a ocorrência do LLA positivo e do pagamento de dividendos, respectivamente, por meio da Correlação Tetracórica. Por tal técnica foi revelada uma intensidade da relação positiva entre tais variáveis de 0,9787 a um $p$-value de 0,000 , esse resultado sugere que o pagamento de dividendos geralmente ocorre apenas quando há LLA positivo. 
Ainda no contexto de classificação de empresas pagadoras, ou não, de dividendos, na Tabela 4 é apresentado o percentual que distribuiu dividendos, conforme classificação por setor econômico. Também é apresentado o resultado do teste Qui-Quadrado, para identificar se existe diferença de média do setor em relação as demais empresas. Tal diferenciação é tomada sob a perspectiva de que setores distintos têm diferenças de necessidades de investimento, sazonalidade e necessidade de capital de giro, e que podem influenciar a necessidade de caixa, consequentemente, a distribuição de dividendos (HEINEBERG; PROCIANOY, 2003), seja, segmentos com maior necessidade de capital de giro tenderiam a reduzir o pagamento de dividendos.

Tabela 4 - Percentual de empresas pagadoras de dividendos por ano e setor econômico

\begin{tabular}{|c|c|c|c|c|c|c|c|c|c|c|c|c|c|}
\hline \multirow{2}{*}{ Setor } & \multicolumn{13}{|c|}{ Amostra (\%) } \\
\hline & 2002 & 2003 & 2004 & 2005 & 2006 & 2007 & 2008 & 2009 & 2010 & 2011 & 2012 & 2013 & Média \\
\hline Agro \& Pesca & - & - & 0 & 0 & 33 & 33 & 67 & 33 & 33 & 33 & 50 & 25 & $31 * * *$ \\
\hline Alimentos e Bebidas & 33 & 33 & 50 & 50 & 63 & 70 & 40 & 80 & 73 & 55 & 62 & 62 & $56^{* * *}$ \\
\hline Comércio & 67 & 70 & 80 & 90 & 83 & 92 & 85 & 79 & 71 & 76 & 65 & 76 & $78 * * *$ \\
\hline Construção & 56 & 50 & 36 & 33 & 80 & 73 & 70 & 82 & 78 & 65 & 43 & 59 & 60 \\
\hline Eletroeletrônica & 67 & 67 & 33 & 25 & 60 & 40 & 83 & 71 & 86 & 57 & 71 & 86 & 62 \\
\hline Energia Elétrica & 30 & 50 & 52 & 72 & 77 & 77 & 87 & 84 & 79 & 79 & 74 & 74 & $70 * *$ \\
\hline Finanças e Seguros / Fundos & 71 & 100 & 100 & 100 & 100 & 100 & 100 & 100 & 96 & 91 & 96 & 91 & $95^{* * *}$ \\
\hline Maquinaria Industrial & 100 & 100 & 100 & 100 & 100 & 100 & 67 & 100 & 100 & 67 & 67 & 67 & $89^{* *}$ \\
\hline Minerais não Metálicos & 50 & 50 & 50 & 50 & 0 & 33 & 33 & 50 & 50 & 50 & 50 & 50 & $43^{* * *}$ \\
\hline Mineração & 33 & 33 & 33 & 33 & 33 & 33 & 33 & 50 & 50 & 50 & 50 & 75 & $42 * * *$ \\
\hline Papel e Celulose & 25 & 75 & 75 & 75 & 75 & 75 & 50 & 75 & 75 & 50 & 50 & 50 & 63 \\
\hline Petróleo e Gás & 100 & 100 & 100 & 75 & 60 & 60 & 80 & 50 & 57 & 57 & 57 & 57 & 71 \\
\hline Química & 100 & 75 & 100 & 100 & 60 & 83 & 50 & 50 & 63 & 63 & 63 & 75 & 74 \\
\hline Siderurgia \& Metalurgia & 79 & 80 & 80 & 75 & 81 & 73 & 59 & 59 & 65 & 59 & 65 & 56 & 69 \\
\hline Software e Dados & - & - & - & 100 & 100 & 100 & 100 & 100 & 100 & 100 & 100 & 100 & $100 * * *$ \\
\hline Telecomunicações & 20 & 60 & 40 & 60 & 80 & 80 & 60 & 33 & 50 & 67 & 67 & 67 & $57 *$ \\
\hline Têxtil & 31 & 38 & 50 & 50 & 47 & 55 & 65 & 67 & 71 & 57 & 57 & 52 & $53 * * *$ \\
\hline Transporte Serviços & 33 & 75 & 100 & 100 & 88 & 88 & 89 & 89 & 89 & 89 & 80 & 90 & $84 * * *$ \\
\hline Veículos e Peças & 38 & 50 & 63 & 56 & 56 & 60 & 60 & 60 & 60 & 70 & 60 & 60 & 58 \\
\hline Outros & 43 & 50 & 48 & 53 & 53 & 57 & 57 & 65 & 68 & 72 & 73 & 69 & $59 * * *$ \\
\hline
\end{tabular}

Nota: Para o teste de Qui-Quadrado, leia-se as seguintes significâncias na tabela: ${ }^{*} \mathrm{p}<, 1 ; * * \mathrm{p}<, 05 ; * * * \mathrm{p}<, 01$

Analisando inicialmente o teste Qui-Quadrado, considerando uma significância de 0,10 , não se pode dizer que há diferenciação de seis dos vinte segmentos econômicos, Construção, Eletroeletrônica, Papel e Celulose, Petróleo e Gás, Química, Siderurgia \& Metalurgia. Ou seja, não se pode dizer que a pertença a esses grupos possa trazer características específicas sobre o pagamento de dividendos.

Conforme apresentado na Tabela 4, a grande maioria das empresas, em seus respectivos setores econômicos, distribuiu dividendos ao longo dos anos. Porém, alguns grupos tiveram maior percentual de distribuição em relação aos demais, como ocorreu com o setor de Software e Dados com 100\% de distribuição nos anos em que esteve presente na amostra. Também se destaca o setor de Finanças e Seguros, em que totalidade das empresas distribuiu dividendos 
nos anos de 2003-2009. Além desses, o setor de Transporte e Serviços e Maquinaria Industrial tiveram alto percentual de empresas pagadoras de dividendos.

Dentre os setores que tiveram menores percentuais de distribuição de dividendos estão os de Agro e Pesca, Alimentos e Bebidas, Minerais não Metálicos, Mineração, Telecomunicações, Têxtil e Veículos e Peças, já que, em média mais de $40 \%$ dessas empresas não distribuíram dividendos no período analisado.

\subsubsection{Valores Distribuídos}

Neste tópico analisa-se as empresas que pagaram dividendos, destacando o montante pago no período de análise e o percentual do Lucro Líquido Ajustado distribuído (payout).

Tomando análise do montante de dividendos e payout médios das empresas que pagaram dividendos ao longo dos anos, apresenta-se a Tabela 5, contendo tais valores deflacionados a janeiro de 2015 pelo Índice Geral de Preços - Disponibilidade Interna (IGPDI).

Tabela 5-Montante de Dividendos e Payout médios pagos

\begin{tabular}{l|c|c|c|c|c|c|c|c|c|c|c|c}
\hline & $\mathbf{2 0 0 2}$ & $\mathbf{2 0 0 3}$ & $\mathbf{2 0 0 4}$ & $\mathbf{2 0 0 5}$ & $\mathbf{2 0 0 6}$ & $\mathbf{2 0 0 7}$ & $\mathbf{2 0 0 8}$ & $\mathbf{2 0 0 9}$ & $\mathbf{2 0 1 0}$ & $\mathbf{2 0 1 1}$ & $\mathbf{2 0 1 2}$ & $\mathbf{2 0 1 3}$ \\
\hline $\begin{array}{l}\text { Montante } \\
\text { (R\$ 10 }\end{array}$ & 281 & 295 & 337 & 378 & 312 & 348 & 326 & 322 & 399 & 401 & 398 & 399 \\
\hline $\begin{array}{l}\text { Payout } \\
\text { Médio }\end{array}$ & $38 \%$ & $44 \%$ & $46 \%$ & $46 \%$ & $52 \%$ & $47 \%$ & $52 \%$ & $51 \%$ & $50 \%$ & $48 \%$ & $56 \%$ & $56 \%$ \\
\hline
\end{tabular}

Quanto a análise do montante médio, comparando os anos de 2002 e 2013 houve aumento do montante de dividendos, porém, nesse espaço de tempo, ocorreram períodos de altas, como de 2002 a 2005, e períodos de baixa, como entre 2008 e 2009 . Também pode ser observado que 2011 foi o ano em que mais se pagou dividendos e 2002 o ano de menor montante. Para as intercorrências destacadas vale ressaltar que 2002 a 2005 foi um período de grande expansão da BM\&FBOVESPA e da econômica brasileira, com crescimento do PIB, o que impulsionou a abertura de capital das empresas e obtenção de melhores lucros. Por sua vez, os anos de 2008 e 2009 estão atrelados a crise econômica mundial o que afetou o Lucro Líquido Ajustado, conforme dados obtidos o ano de 2008 foi um ano de queda do LLA médio.

Analisando o payout médio distribuído, como apresentado na Tabela 5, os percentuais médios de payout variaram entre 38\% (2002) e 56\% (2012 e 2013), os menores payout's ocorreram nos anos de $2002(38 \%)$ e 2003(44\%) e as maiores em 2012 e 2013 (56\%). Nisso vale destacar que em todos os anos a média deste indicador esteve maior do que os $25 \%$, majoritariamente adotado pelas empresas como payout mínimo estatutário, isso já indica uma preferência no pagamento do chamado payout incremental, o que é analisado em tópico posterior.

Passando-se análise por setor econômico, apresenta-se a seguir a tabela 6, onde é evidendciado o payout médio das empresas por setor e a razão dividend yield (razão enre dividendos distribuídos e o valor de mercado da empresa). Também é apresentado na tabela o teste de diferença de amostras de Kruskal Wallis, que indica se há diferença entre determinado setor e os demais.

Optou-se por discutir o Dividend yield e não o montante de dividendos pagos para que haja mehor comparação entre as empresas analisadas e, segundo Jensen e Mekling (1976) é um dos indicadores que os acionistas utilizam para tomar decisão de investimento quando o assunto é pagamento de dividendos. 
Tabela 6 - Ranking Payout e Dividend Yield médios por setor econômico

\begin{tabular}{|c|c|c|c|c|c|c|}
\hline \multirow{3}{*}{$\begin{array}{l}\text { Setor } \\
\text { Agro \& Pesca }\end{array}$} & \multicolumn{3}{|c|}{ Dividend Yield } & \multicolumn{3}{|c|}{ Payout } \\
\hline & \multicolumn{2}{|c|}{ Média } & \multirow{2}{*}{$\frac{\text { Ranking }}{20^{\circ}}$} & \multicolumn{2}{|c|}{ Média } & \multirow{2}{*}{$\frac{\text { Ranking }}{18^{\circ}}$} \\
\hline & $1,0 \%$ & $* * *$ & & $36 \%$ & & \\
\hline Alimentos e Bebidas & $1,7 \%$ & $* * *$ & $19^{\circ}$ & $35 \%$ & $* * *$ & $19^{\circ}$ \\
\hline Comércio & $1,9 \%$ & $* * *$ & $18^{\circ}$ & $46 \%$ & $*$ & $13^{\circ}$ \\
\hline Construção & $3,3 \%$ & * & $6^{\circ}$ & $30 \%$ & $* * *$ & $20^{\circ}$ \\
\hline Eletroeletrônica & $4,0 \%$ & & $4^{\circ}$ & $59 \%$ & $* *$ & $5^{\circ}$ \\
\hline Energia Elétrica & $5,3 \%$ & $* * *$ & $1^{\circ}$ & $72 \%$ & $* * *$ & $1^{\circ}$ \\
\hline Finanças e Seguros / Fundos & $4,1 \%$ & ** & $3^{\circ}$ & $46 \%$ & & $12^{\circ}$ \\
\hline Maquinaria Industrial & $3,3 \%$ & & $5^{\circ}$ & $70 \%$ & $* * *$ & $2^{\circ}$ \\
\hline Minerais não Metálicos & $2,2 \%$ & & $15^{\circ}$ & $47 \%$ & & $9^{\circ}$ \\
\hline Mineração & $4,6 \%$ & $* *$ & $2^{\circ}$ & $46 \%$ & & $11^{\circ}$ \\
\hline Papel e Celulose & $2,4 \%$ & & $13^{\circ}$ & $44 \%$ & & $15^{\circ}$ \\
\hline Petróleo e Gás & $2,3 \%$ & & $14^{\circ}$ & $42 \%$ & & $16^{\circ}$ \\
\hline Química & $2,7 \%$ & & $11^{\circ}$ & $52 \%$ & & $7^{\circ}$ \\
\hline Siderurgia \& Metalurgia & $2,7 \%$ & & $10^{\circ}$ & $37 \%$ & $* *$ & $17^{\circ}$ \\
\hline Software e Dados & $2,1 \%$ & & $16^{\circ}$ & $65 \%$ & $* * *$ & $4^{\circ}$ \\
\hline Telecomunicações & $3,1 \%$ & & $7^{\circ}$ & $69 \%$ & & $3^{\circ}$ \\
\hline Têxtil & $2,8 \%$ & & $9^{\circ}$ & $49 \%$ & & $8^{\circ}$ \\
\hline Transporte Serviço & $2,1 \%$ & $* *$ & $17^{\circ}$ & $56 \%$ & & $6^{\circ}$ \\
\hline Veículos e Peças & $2,9 \%$ & & $8^{\circ}$ & $45 \%$ & & $14^{\circ}$ \\
\hline Outros & $2,6 \%$ & $* * *$ & $12^{\circ}$ & $46 \%$ & $* * *$ & $10^{\circ}$ \\
\hline Média & $2,9 \%$ & $* * *$ & - & $49,6 \%$ & $* * *$ & \\
\hline
\end{tabular}

Nota: Para o teste de Krukal Wallis, leia-se as seguintes significâncias na tabela: ${ }^{*} \mathrm{p}<, 1 ; * *$ $\mathrm{p}<, 05 ; * * * \mathrm{p}<, 01$

Conforme apresentado, das empresas que pagaram dividendos, os setores econômicos com maiores Dividend Yield são Energia Elétrica, Mineração e Finanças, com índices de 0,053, 0,046 e 0,041 , respectivamente, todos estes rejeitando a hipótese de igualdade de amostras. Por sua vez, ao observar o payout médio dos grupos econômicos o setor Energia Elétrica é o que distribui maior parte de seu Lucro Líquido ajustado, seguido do setor de Maquinaria Industrial e Telecomunicações, entretanto neste último não se pode rejeitar a hipótese de igualdade de amostras. Vale rememorar que o setor de Energia Elétrica é um dos grupos que tem maior número de empresas com payout mínimo estatutário acima de $25 \%$, como apresentado anteriormente no Quadro 5.

\subsubsection{Forma de Pagamento}

Aborda-se então a forma adotada pelas empresas para distribuição de dividendos, observando se optaram por pagar apenas dividendos, apenas JSCP ou as duas formas, dividendos e JSCP. Os dados são apresentados na Tabela 7. 
Tabela 7 - Classificação quanto a forma de distribuição

\begin{tabular}{|l|r|r|r|r|r|r|r|r|r|r|r|c|}
\hline $\begin{array}{l}\text { Forma de } \\
\text { Distribuição }\end{array}$ & $\mathbf{2 0 0 2}$ & $\mathbf{2 0 0 3}$ & $\mathbf{2 0 0 4}$ & $\mathbf{2 0 0 5}$ & $\mathbf{2 0 0 6}$ & $\mathbf{2 0 0 7}$ & $\mathbf{2 0 0 8}$ & $\mathbf{2 0 0 9}$ & $\mathbf{2 0 1 0}$ & $\mathbf{2 0 1 1}$ & $\mathbf{2 0 1 2}$ & $\mathbf{2 0 1 3}$ \\
\hline Só Dividendos & $54 \%$ & $43 \%$ & $43 \%$ & $45 \%$ & $57 \%$ & $56 \%$ & $57 \%$ & $58 \%$ & $55 \%$ & $56 \%$ & $57 \%$ & $58 \%$ \\
\hline Só JSCP & $35 \%$ & $34 \%$ & $34 \%$ & $27 \%$ & $19 \%$ & $16 \%$ & $15 \%$ & $15 \%$ & $18 \%$ & $14 \%$ & $12 \%$ & $13 \%$ \\
\hline Divid. e JSCP & $11 \%$ & $23 \%$ & $23 \%$ & $28 \%$ & $24 \%$ & $28 \%$ & $28 \%$ & $28 \%$ & $28 \%$ & $30 \%$ & $31 \%$ & $30 \%$ \\
\hline Pagadores & 71 & 93 & 100 & 115 & 145 & 162 & 170 & 186 & 201 & 194 & 194 & 196 \\
\hline
\end{tabular}

As informações da Tabela 7 mostram que em quase todos os anos a maioria das empresas optaram por distribuir seus lucros apenas como dividendos, com exceção dos anos de 2003, 2004 e 2005. Também, com exceção dos anos de 2003 a 2005, os valores percentuais das empresas que adoram apenas os dividendos se mantém entre $54 \%$ e $58 \%$.

As empresas que utilizam apenas os JSCP estão em torno de $12 \%$ a $18 \%$ das empresas pagadoras. Analisando os anos estudados, pode ser observado uma queda do percentual de empresas que adotaram apenas JSCP, exceto em 2008 quando houve crescimento, tendo em vista que em $200235 \%$ das empresas constantes na amostra optaram apenas pelos JSCP e apenas cerca de $13 \%$ das empresas em 2013.

Quanto ao grupo que adota concomitantemente JSCP e dividendos, os dados mostram que houveram crescimentos percentuais ente os anos de 2004, 2006, 2011 e 2013 e em um contexto geral também houve aumento em valores percentuais e absolutos de empresas nesse grupo, pois, em 2002 representavam 11\% da amostra (8 empresas) e em 2013 30\% (58 empresas).

Passa-se a análise da continuidade da forma de pagamento, ou seja, se as empresas da amostra que adotaram determinada forma de pagamento a seguiram adotando no período analisado, ou não. Para isso são apresentadas a seguir três tabelas, na Tabela 8 observa-se a continuidade de pagamento apenas na forma de dividendos, na Tabela 9 apenas na forma de JSCP e na Tabela 10 as que optaram concomitantemente por dividendos e JSCP. Para interpretação combinam-se as informações das linhas com as das colunas, destacando que na primeira coluna está o percentual da amostra que adotou determinada forma de distribuição na segunda e terceira, na segunda e na terceira se distribuiu outras formas ou não.

Tabela 8 - Continuidade em pagar apenas dividendos

\begin{tabular}{|l|c|c|c|}
\hline Forma de Remuneração & Total & Distribuiu Outras Formas & Distribuiu Apenas Dividendos \\
\hline Outras Formas & $48,22 \%$ & $91,26 \%$ & $8,74 \%$ \\
\hline Apenas Dividendos & $51,78 \%$ & $9,18 \%$ & $90,82 \%$ \\
\hline
\end{tabular}

Conforme dados da Tabela 8, em 51,78\% das vezes optou-se por remunerar os sócios apenas com dividendos, sem adoção de JSCP. Nas quais, em 90,82\% adotou-se esta prática por todo período analisado e em $9,18 \%$ optou-se por uma outra forma de pagamento (apenas JSCP ou concomitantemente JSCP e Dividendos). Por outro lado, dos 48,22\% das vezes em que as empresas aderiram unicamente ao pagamento de dividendos, em 91,26\% assim se mantiveram e em $8,74 \%$ distribuiu apenas dividendos.

Voltando-se a análise da continuidade em pagar apenas JSCP, como apresentado na Tabela 9, tem-se que $18,60 \%$ das empresas que mantiveram alguma continuidade de distribuição de proventos aos sócios adotaram apenas JSCP e $81.40 \%$ não.

Tabela 9 - Continuidade em pagar apenas JSCP

\begin{tabular}{|c|c|c|c|}
\hline $\begin{array}{c}\text { Forma de } \\
\text { Remuneração }\end{array}$ & Total & Distribuiu Outras Formas & Distribuiu Apenas JSCP \\
\hline Outras Formas & $81,40 \%$ & $94,00 \%$ & $6,00 \%$ \\
\hline Apenas JSCP & $18,60 \%$ & $30,33 \%$ & $69,67 \%$ \\
\hline
\end{tabular}


Ainda segundo dados da Tabela 9, das empresas que optaram em pagar apenas JSCP $(18,60 \%), 69,67 \%$ o fizeram em todo o período da análise e 30,33\% adotaram outra forma (apenas dividendos ou concomitantemente dividendos e JSCP). Quanto aquelas que não adotaram $(81,40 \%), 94,00 \%$ assim se mantiveram durante o período e 30,33\% optaram por outra forma de remuneração.

Por fim, apresenta-se a Tabela 10, com os percentuais de continuidade de pagamento de dividendos e JSCP em conjunto.

Tabela 10- Continuidade em pagar conjuntamente Dividendos e JSCP

\begin{tabular}{|l|c|c|c|}
\hline $\begin{array}{c}\text { Forma de } \\
\text { Remuneração }\end{array}$ & Total & Distribuiu Outras Formas & Distribuiu JSCP e Dividendos \\
\hline Outras Formas & $70,38 \%$ & $84,95 \%$ & $12,05 \%$ \\
\hline JSCP e Dividendos & $29,62 \%$ & $24,70 \%$ & $75,30 \%$ \\
\hline
\end{tabular}

Das empresas que optaram por usar concomitantemente JSCP e Dividendos, representando $29,62 \%$ da amostra, 75,30\% continuou pagando dividendos e JSCP e $24,70 \%$ adotou outra forma de remuneração dos acionistas (apenas dividendos ou apenas JSCP). Quanto as empresas que não adotaram esta forma $(70,38 \%), 84,95 \%$ assim continuaram durante o período de análise, e 24,70\% resolveu utilizar outra forma de remuneração.

Conforme dados das Tabelas $7-10$, é possível notar a preferência das empresas pagadoras em adotar dividendos a apenas JSCP. Neste contexto, buscou-se investigar se a preferência pelo pagamento de dividendos pode ser motivada pela predominância de acionistas majoritários na forma de pessoa jurídica, o que indicaria um conflito de agência decorrente da dicotômica (des)vantagem tributária entre os agentes, conforme discutido no tópico 0 , apresentado anteriormente. Para tanto, seguindo a perspectiva descritiva deste estudo, observou-se a associação entre as variáveis que identificam a forma de pagamento de dividendos $\left(\boldsymbol{S D i v}{ }_{t}, \boldsymbol{S J S C P} \boldsymbol{P}_{t} \boldsymbol{e} \mathbf{D i v} \boldsymbol{\&} \boldsymbol{J S C P} \boldsymbol{P}_{t}\right)$ e a personificação do acionista majoritário $\left(\boldsymbol{A c m a j}_{t}\right)$, a técnica utilizada foi a correlação tetracórica, haja vista serem variáveis contínuas transformadas em categóricas, os resultados são apresentados na Tabela 11.

Tabela 11 - Correlação Tetracórica forma de pagamento de dividendos e personificação do acionista majoritário

\begin{tabular}{|c|c|c|c|c|}
\hline & $\begin{array}{c}\text { Só } \\
\text { Dividendos } \\
\end{array}$ & $\begin{array}{c}\text { Só } \\
\text { JSCP } \\
\end{array}$ & $\begin{array}{c}\text { Dividendos } \\
\text { e JSCP }\end{array}$ & Acmajt $_{t}$ \\
\hline Só Dividendos (SDivt) & 1,0000 & & & \\
\hline Só JSCP $\left(S J S C P_{t}\right)$ & $-1,0000$ & 1,0000 & & \\
\hline Dividendos e JSCP (Div\&JSCP $)$ & $-1,0000$ & $-1,0000$ & 1,0000 & \\
\hline$A c m a j t$ & 0,0352 & $-0,1178$ & $\mathbf{0 , 0 5 8 6}$ & 1,000 \\
\hline
\end{tabular}

Conforme pode ser visto na Tabela 11 , tem-se correlações positivas entre a variável

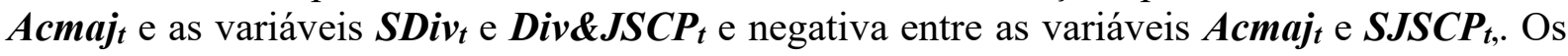
resultados indicam que empresas que tem seu principal acionista majoritário personificado como pessoa jurídica seguiram a distribuição lucros na forma de dividendos ou na forma de dividendos e juros sobre capital próprio. Por sua vez, diante do valor negativo da correlação, tais empresas não buscaram distribuir dividendos apenas na forma de juros sobre capital próprio. Com esses resultados entende-se que há indícios de ocorrência do conflito de agência.

O conflito de agência ocorreria por interesses divergentes na distribuição dos lucros entre os acionistas majoritários personificados como pessoa jurídica e os demais agentes que tem interesse na maximização do fluxo de caixa da empresa, como acionistas personificados 
como pessoa física. Nesse caso, os acionistas majoritários estariam agindo em interesse próprio, com o intuito de ter menores desembolsos tributários pelo recebimento de dividendos, o que faz com que a empresa pagadora não usufrua da vantagem tributária quando do pagamento de JSCP, reduzindo, assim, seu fluxo de caixa e, por conseguinte, não investimento em possíveis projetos rentáveis.

Tendo discutido no decorrer do tópico 4.2 e seus subtópicos o quantitativo de dividendos distribuído os valores de payout e a forma de distribuição, passa-se à classificação das empresas quanto aos níveis de payout distribuídos e sua análise.

\subsection{Os Níveis de Payout}

Neste tópico é discutido o nível de payout, incremental, mínimo ou reduzido, adotado pelas empresas pagadoras de dividendos para o período analisado e em sequência a análise de continuidade, semelhante ao realizado com o pagamento e forma de dividendos.

$\mathrm{Na}$ Tabela 12, é apresentado o percentual de empresas pagadoras de dividendos que distribuíram payout incremental, mínimo e reduzido, ao longo do período estudado.

Tabela 12 - Classificação das empresas quanto ao nível de payout

\begin{tabular}{l|r|r|r|r|r|r|r|r|r|r|r|c}
$\begin{array}{l}\text { Nível de } \\
\text { Payout }\end{array}$ & $\mathbf{2 0 0 2}$ & $\mathbf{2 0 0 3}$ & $\mathbf{2 0 0 4}$ & $\mathbf{2 0 0 5}$ & $\mathbf{2 0 0 6}$ & $\mathbf{2 0 0 7}$ & $\mathbf{2 0 0 8}$ & $\mathbf{2 0 0 9}$ & $\mathbf{2 0 1 0}$ & $\mathbf{2 0 1 1}$ & $\mathbf{2 0 1 2}$ & $\mathbf{2 0 1 3}$ \\
\hline Incremental & $63 \%$ & $69 \%$ & $65 \%$ & $65 \%$ & $69 \%$ & $60 \%$ & $69 \%$ & $66 \%$ & $65 \%$ & $61 \%$ & $70 \%$ & $69 \%$ \\
\hline Mínimo & $23 \%$ & $14 \%$ & $13 \%$ & $17 \%$ & $17 \%$ & $25 \%$ & $15 \%$ & $20 \%$ & $23 \%$ & $27 \%$ & $19 \%$ & $20 \%$ \\
\hline Reduzido & $14 \%$ & $17 \%$ & $22 \%$ & $18 \%$ & $14 \%$ & $15 \%$ & $15 \%$ & $13 \%$ & $12 \%$ & $12 \%$ & $11 \%$ & $10 \%$ \\
\hline Pagadores & 71 & 93 & 100 & 115 & 145 & 162 & 170 & 186 & 201 & 194 & 194 & 196 \\
\hline
\end{tabular}

Conforme dados da referida tabela, mais de $60 \%$ das empresas da amostra distribuiu dividendos incrementais. Enquanto que o percentual das que pagaram o mínimo estabelecido variou entre $13 \%$ (2004) e 27\% (2011) e as que distribuíram abaixo deste mínimo representaram entre $10 \%$ (2013) e $22 \%$ da amostra (2004). Com isso, pode-se dizer que mesmo que haja uma uniformização do percentual de dividendos mínimos estabelecidos, a maioria das empresas tende a não o seguir.

Vancin e Procianoy (2014) encontraram percentual próximo para empresas pagadoras de dividendos incrementais em seu estudo. Analisando os anos de 2007 a 2011, identificaram que 60\% (2007), 64,4\% (2008), 67,9\% (2009), 63,6\% (2010) e 64,6\% (2011) das empresas distribuíram dividendos acima do mínimo estabelecido.

Quanto aos valores de payout mínimo e reduzido, acredita-se que os referidos autores agregaram esses dois grupos, por isso, números mais distantes nos percentuais de dividendos mínimos.

Passando-se a análise dos níveis de dividendos conforme setor econômico, apresenta-se a Tabela 13, onde são discriminados os percentuais de empresas que distribuíram dividendos, conforme seu nível. 
Tabela 13 - Níveis de payout por setor econômico

\begin{tabular}{|c|c|c|c|c|c|c|c|c|c|c|c|c|c|c|}
\hline Setor Econômico & Nível de Payout & 2002 & 2003 & 2004 & 2005 & 2006 & 2007 & 2008 & 2009 & 2010 & 2011 & 2012 & 2013 & Total \\
\hline \multirow[t]{4}{*}{ Agro \& Pesca } & Incremental & - & - & - & - & $100 \%$ & $0 \%$ & $50 \%$ & $0 \%$ & $0 \%$ & $100 \%$ & $100 \%$ & $100 \%$ & $60 \%$ \\
\hline & Mínimo & - & - & - & - & $0 \%$ & $100 \%$ & $0 \%$ & $100 \%$ & $100 \%$ & $0 \%$ & $0 \%$ & $0 \%$ & $30 \%$ \\
\hline & Reduzido & - & - & - & - & $0 \%$ & $0 \%$ & $50 \%$ & $0 \%$ & $0 \%$ & $0 \%$ & $0 \%$ & $0 \%$ & $10 \%$ \\
\hline & N. Pagadores & $\mathbf{0}$ & $\mathbf{0}$ & $\mathbf{0}$ & $\mathbf{0}$ & 1 & 1 & 2 & 1 & 1 & 1 & 2 & 1 & 10 \\
\hline \multirow[t]{4}{*}{ Alimentos e Bebidas } & Incremental & $0 \%$ & $0 \%$ & $50 \%$ & $33 \%$ & $40 \%$ & $43 \%$ & $50 \%$ & $50 \%$ & $38 \%$ & $50 \%$ & $75 \%$ & $63 \%$ & $49 \%$ \\
\hline & Mínimo & $100 \%$ & $0 \%$ & $0 \%$ & $33 \%$ & $20 \%$ & $43 \%$ & $25 \%$ & $13 \%$ & $38 \%$ & $33 \%$ & $25 \%$ & $38 \%$ & $30 \%$ \\
\hline & Reduzido & $0 \%$ & $100 \%$ & $50 \%$ & $33 \%$ & $40 \%$ & $14 \%$ & $25 \%$ & $38 \%$ & $25 \%$ & $17 \%$ & $0 \%$ & $0 \%$ & $21 \%$ \\
\hline & N. Pagadores & 1 & 1 & 2 & 3 & 5 & 7 & 4 & 8 & 8 & 6 & 8 & 8 & 61 \\
\hline \multirow{4}{*}{ Comércio } & Incremental & $50 \%$ & $57 \%$ & $75 \%$ & $78 \%$ & $60 \%$ & $73 \%$ & $27 \%$ & $45 \%$ & $50 \%$ & $46 \%$ & $45 \%$ & $62 \%$ & $55 \%$ \\
\hline & Mínimo & $33 \%$ & $14 \%$ & $25 \%$ & $11 \%$ & $30 \%$ & $9 \%$ & $64 \%$ & $36 \%$ & $33 \%$ & $38 \%$ & $36 \%$ & $31 \%$ & $31 \%$ \\
\hline & Reduzido & $17 \%$ & $29 \%$ & $0 \%$ & $11 \%$ & $10 \%$ & $18 \%$ & $9 \%$ & $18 \%$ & $17 \%$ & $15 \%$ & $18 \%$ & $8 \%$ & $14 \%$ \\
\hline & N. Pagadores & 6 & 7 & 8 & 9 & 10 & 11 & 11 & 11 & 12 & 13 & 11 & 13 & 122 \\
\hline \multirow[t]{4}{*}{ Construção } & Incremental & $40 \%$ & $80 \%$ & $75 \%$ & $50 \%$ & $38 \%$ & $13 \%$ & $44 \%$ & $28 \%$ & $22 \%$ & $27 \%$ & $30 \%$ & $31 \%$ & $33 \%$ \\
\hline & Mínimo & $20 \%$ & $20 \%$ & $25 \%$ & $25 \%$ & $56 \%$ & $75 \%$ & $25 \%$ & $67 \%$ & $72 \%$ & $60 \%$ & $50 \%$ & $54 \%$ & $54 \%$ \\
\hline & Reduzido & $40 \%$ & $0 \%$ & $0 \%$ & $25 \%$ & $6 \%$ & $13 \%$ & $31 \%$ & $6 \%$ & $6 \%$ & $13 \%$ & $20 \%$ & $15 \%$ & $14 \%$ \\
\hline & N. Pagadores & 5 & 5 & 4 & 4 & 16 & 16 & 16 & 18 & 18 & 15 & 10 & 13 & 140 \\
\hline \multirow[t]{4}{*}{ Eletroeletrônica } & Incremental & $50 \%$ & $100 \%$ & $100 \%$ & $100 \%$ & $67 \%$ & $50 \%$ & $100 \%$ & $80 \%$ & $100 \%$ & $50 \%$ & $60 \%$ & $83 \%$ & $79 \%$ \\
\hline & Mínimo & $50 \%$ & $0 \%$ & $0 \%$ & $0 \%$ & $33 \%$ & $50 \%$ & $0 \%$ & $20 \%$ & $0 \%$ & $50 \%$ & $40 \%$ & $17 \%$ & $21 \%$ \\
\hline & Reduzido & $0 \%$ & $0 \%$ & $0 \%$ & $0 \%$ & $0 \%$ & $0 \%$ & $0 \%$ & $0 \%$ & $0 \%$ & $0 \%$ & $0 \%$ & $0 \%$ & $0 \%$ \\
\hline & N. Pagadores & 2 & 2 & 1 & 1 & 3 & 2 & 5 & 5 & 6 & 4 & 5 & 6 & 42 \\
\hline \multirow[t]{4}{*}{ Energia Elétrica } & Incremental & $67 \%$ & $64 \%$ & $58 \%$ & $56 \%$ & $74 \%$ & $83 \%$ & $96 \%$ & $77 \%$ & $93 \%$ & $74 \%$ & $76 \%$ & $84 \%$ & $78 \%$ \\
\hline & Mínimo & $17 \%$ & $9 \%$ & $8 \%$ & $17 \%$ & $9 \%$ & $8 \%$ & $0 \%$ & $12 \%$ & $4 \%$ & $11 \%$ & $16 \%$ & $12 \%$ & $10 \%$ \\
\hline & Reduzido & $17 \%$ & $27 \%$ & $33 \%$ & $28 \%$ & $17 \%$ & $8 \%$ & $4 \%$ & $12 \%$ & $4 \%$ & $15 \%$ & $8 \%$ & $4 \%$ & $12 \%$ \\
\hline & N. Pagadores & 6 & 11 & 12 & 18 & 23 & 24 & 27 & 26 & 27 & 27 & 25 & 25 & 251 \\
\hline \multirow[t]{4}{*}{ Finanças e Seguros } & Incremental & $80 \%$ & $44 \%$ & $56 \%$ & $60 \%$ & $85 \%$ & $65 \%$ & $84 \%$ & $86 \%$ & $77 \%$ & $86 \%$ & $82 \%$ & $81 \%$ & $77 \%$ \\
\hline & Mínimo & $20 \%$ & $22 \%$ & $22 \%$ & $10 \%$ & $8 \%$ & $24 \%$ & $11 \%$ & $10 \%$ & $14 \%$ & $14 \%$ & $9 \%$ & $10 \%$ & $13 \%$ \\
\hline & Reduzido & $0 \%$ & $33 \%$ & $22 \%$ & $30 \%$ & $8 \%$ & $12 \%$ & $5 \%$ & $5 \%$ & $9 \%$ & $0 \%$ & $9 \%$ & $10 \%$ & $10 \%$ \\
\hline & N. Pagadores & 5 & 9 & 9 & 10 & 13 & 17 & 19 & 21 & 22 & 21 & 22 & 21 & 189 \\
\hline \multirow{4}{*}{ Maquinaria Industrial } & Incremental & $100 \%$ & $100 \%$ & $100 \%$ & $100 \%$ & $100 \%$ & $100 \%$ & $100 \%$ & $100 \%$ & $100 \%$ & $100 \%$ & $100 \%$ & $100 \%$ & $100 \%$ \\
\hline & Mínimo & $0 \%$ & $0 \%$ & $0 \%$ & $0 \%$ & $0 \%$ & $0 \%$ & $0 \%$ & $0 \%$ & $0 \%$ & $0 \%$ & $0 \%$ & $0 \%$ & $0 \%$ \\
\hline & Reduzido & $0 \%$ & $0 \%$ & $0 \%$ & $0 \%$ & $0 \%$ & $0 \%$ & $0 \%$ & $0 \%$ & $0 \%$ & $0 \%$ & $0 \%$ & $0 \%$ & $0 \%$ \\
\hline & N. Pagadores & 2 & 2 & 2 & 2 & 2 & 3 & 2 & 3 & 3 & 2 & 2 & 2 & 27 \\
\hline
\end{tabular}


Continuação

\begin{tabular}{|c|c|c|c|c|c|c|c|c|c|c|c|c|c|c|}
\hline Setor Econômico & Nível de Pavout & 2002 & 2003 & 2004 & 2005 & 2006 & 2007 & & & & & & & \\
\hline \multirow{5}{*}{ Mineração } & & $100 \%$ & & & & & & & & & & & & \\
\hline & Incremental & $100 \%$ & $100 \%$ & $100 \%$ & $100 \%$ & - & $100 \%$ & $100 \%$ & $100 \%$ & $100 \%$ & $0 \%$ & $50 \%$ & $100 \%$ & $81 \%$ \\
\hline & Mínimo & $0 \%$ & $0 \%$ & $0 \%$ & $0 \%$ & - & $0 \%$ & $0 \%$ & $0 \%$ & $0 \%$ & $100 \%$ & $50 \%$ & $0 \%$ & $19 \%$ \\
\hline & Reduzido & $0 \%$ & $0 \%$ & $0 \%$ & $0 \%$ & - & $0 \%$ & $0 \%$ & $0 \%$ & $0 \%$ & $0 \%$ & $0 \%$ & $0 \%$ & $0 \%$ \\
\hline & N. Pagadores & 1 & 1 & 1 & 1 & $\mathbf{0}$ & 1 & 1 & 2 & 2 & 2 & 2 & 2 & 16 \\
\hline \multirow[t]{4}{*}{ Minerais não Metálicos } & Incremental & $0 \%$ & $0 \%$ & $100 \%$ & $100 \%$ & $100 \%$ & $100 \%$ & $100 \%$ & $100 \%$ & $100 \%$ & $50 \%$ & $100 \%$ & $100 \%$ & $83 \%$ \\
\hline & Mínimo & $100 \%$ & $100 \%$ & $0 \%$ & $0 \%$ & $0 \%$ & $0 \%$ & $0 \%$ & $0 \%$ & $0 \%$ & $50 \%$ & $0 \%$ & $0 \%$ & $17 \%$ \\
\hline & Reduzido & $0 \%$ & $0 \%$ & $0 \%$ & $0 \%$ & $0 \%$ & $0 \%$ & $0 \%$ & $0 \%$ & $0 \%$ & $0 \%$ & $0 \%$ & $0 \%$ & $0 \%$ \\
\hline & N. Pagadores & 1 & 1 & 1 & 1 & 1 & 1 & 1 & 2 & 2 & 2 & 2 & 3 & 18 \\
\hline \multirow[t]{4}{*}{ Papel e Celulose } & Incremental & $100 \%$ & $67 \%$ & $67 \%$ & $67 \%$ & $67 \%$ & $67 \%$ & $100 \%$ & $33 \%$ & $33 \%$ & $50 \%$ & $50 \%$ & $50 \%$ & $60 \%$ \\
\hline & Mínimo & $0 \%$ & $0 \%$ & $0 \%$ & $33 \%$ & $33 \%$ & $0 \%$ & $0 \%$ & $0 \%$ & $67 \%$ & $50 \%$ & $50 \%$ & $50 \%$ & $23 \%$ \\
\hline & Reduzido & $0 \%$ & $33 \%$ & $33 \%$ & $0 \%$ & $0 \%$ & $33 \%$ & $0 \%$ & $67 \%$ & $0 \%$ & $0 \%$ & $0 \%$ & $0 \%$ & $17 \%$ \\
\hline & N. Pagadores & 1 & 3 & 3 & 3 & 3 & 3 & 2 & 3 & 3 & 2 & 2 & 2 & 30 \\
\hline \multirow[t]{4}{*}{ Petróleo e Gás } & Incremental & $75 \%$ & $75 \%$ & $75 \%$ & $100 \%$ & $100 \%$ & $100 \%$ & $75 \%$ & $67 \%$ & $75 \%$ & $75 \%$ & $100 \%$ & $50 \%$ & $80 \%$ \\
\hline & Mínimo & $25 \%$ & $25 \%$ & $0 \%$ & $0 \%$ & $0 \%$ & $0 \%$ & $0 \%$ & $33 \%$ & $25 \%$ & $25 \%$ & $0 \%$ & $50 \%$ & $16 \%$ \\
\hline & Reduzido & $0 \%$ & $0 \%$ & $25 \%$ & $0 \%$ & $0 \%$ & $0 \%$ & $25 \%$ & $0 \%$ & $0 \%$ & $0 \%$ & $0 \%$ & $0 \%$ & $5 \%$ \\
\hline & N. Pagadores & 4 & 4 & 4 & 3 & 3 & 3 & 4 & 3 & 4 & 4 & 4 & 4 & 44 \\
\hline \multirow[t]{4}{*}{ Química } & Incremental & $50 \%$ & $0 \%$ & $50 \%$ & $75 \%$ & $67 \%$ & $40 \%$ & $75 \%$ & $100 \%$ & $80 \%$ & $60 \%$ & $60 \%$ & $83 \%$ & $63 \%$ \\
\hline & Mínimo & $25 \%$ & $33 \%$ & $0 \%$ & $0 \%$ & $0 \%$ & $20 \%$ & $25 \%$ & $0 \%$ & $20 \%$ & $20 \%$ & $0 \%$ & $0 \%$ & $12 \%$ \\
\hline & Reduzido & $25 \%$ & $67 \%$ & $50 \%$ & $25 \%$ & $33 \%$ & $40 \%$ & $0 \%$ & $0 \%$ & $0 \%$ & $20 \%$ & $40 \%$ & $17 \%$ & $25 \%$ \\
\hline & N. Pagadores & 4 & 3 & 4 & 4 & 3 & 5 & 4 & 4 & 5 & 5 & 5 & 6 & 52 \\
\hline \multirow{4}{*}{ Siderurgia \& Metalurgia } & Incremental & $64 \%$ & $75 \%$ & $67 \%$ & $75 \%$ & $77 \%$ & $73 \%$ & $50 \%$ & $70 \%$ & $64 \%$ & $70 \%$ & $73 \%$ & $78 \%$ & $70 \%$ \\
\hline & Mínimo & $9 \%$ & $8 \%$ & $17 \%$ & $17 \%$ & $15 \%$ & $18 \%$ & $30 \%$ & $20 \%$ & $27 \%$ & $30 \%$ & $27 \%$ & $22 \%$ & $20 \%$ \\
\hline & Reduzido & $27 \%$ & $17 \%$ & $17 \%$ & $8 \%$ & $8 \%$ & $9 \%$ & $20 \%$ & $10 \%$ & $9 \%$ & $0 \%$ & $0 \%$ & $0 \%$ & $11 \%$ \\
\hline & N. Pagadores & 11 & 12 & 12 & 12 & 13 & 11 & 10 & 10 & 11 & 10 & 11 & 9 & 132 \\
\hline \multirow[t]{4}{*}{ Software e Dados } & Incremental & - & - & - & $100 \%$ & $100 \%$ & $100 \%$ & $100 \%$ & $100 \%$ & $100 \%$ & $100 \%$ & $100 \%$ & $100 \%$ & $100 \%$ \\
\hline & Mínimo & - & - & - & $0 \%$ & $0 \%$ & $0 \%$ & $0 \%$ & $0 \%$ & $0 \%$ & $0 \%$ & $0 \%$ & $0 \%$ & $0 \%$ \\
\hline & Reduzido & - & - & - & $0 \%$ & $0 \%$ & $0 \%$ & $0 \%$ & $0 \%$ & $0 \%$ & $0 \%$ & $0 \%$ & $0 \%$ & $0 \%$ \\
\hline & N. Pagadores & $\mathbf{0}$ & $\mathbf{0}$ & $\mathbf{0}$ & 1 & 1 & 1 & 1 & 2 & 2 & 3 & 4 & 4 & 19 \\
\hline \multirow[t]{3}{*}{ Telecomunicações } & Incremental & $100 \%$ & $67 \%$ & $50 \%$ & $100 \%$ & $100 \%$ & $50 \%$ & $67 \%$ & $50 \%$ & $33 \%$ & $100 \%$ & $75 \%$ & $100 \%$ & $76 \%$ \\
\hline & Mínimo & $0 \%$ & $33 \%$ & $0 \%$ & $0 \%$ & $0 \%$ & $50 \%$ & $33 \%$ & $50 \%$ & $0 \%$ & $0 \%$ & $25 \%$ & $0 \%$ & $16 \%$ \\
\hline & Reduzido & $0 \%$ & $0 \%$ & $50 \%$ & $0 \%$ & $0 \%$ & $0 \%$ & $0 \%$ & $0 \%$ & $67 \%$ & $0 \%$ & $0 \%$ & $0 \%$ & $8 \%$ \\
\hline \multicolumn{15}{|c|}{ Continua } \\
\hline
\end{tabular}


Tabela 13 - Níveis de payout por setor econômico

\begin{tabular}{|c|c|c|c|c|c|c|c|c|c|c|c|c|c|c|}
\hline Setor Econômico & Nível de Payout & 2002 & 2003 & 2004 & 2005 & 2006 & 2007 & 2008 & 2009 & 2010 & 2011 & 2012 & 2013 & Total \\
\hline Telecomunicações & N. Pagadores & 1 & 3 & 2 & 3 & 4 & 4 & 3 & 2 & 3 & 4 & 4 & 4 & 37 \\
\hline \multirow[t]{4}{*}{ Têxtil } & Incremental & $40 \%$ & $67 \%$ & $67 \%$ & $44 \%$ & $56 \%$ & $64 \%$ & $77 \%$ & $71 \%$ & $67 \%$ & $67 \%$ & $83 \%$ & $55 \%$ & $65 \%$ \\
\hline & Mínimo & $60 \%$ & $33 \%$ & $22 \%$ & $44 \%$ & $33 \%$ & $18 \%$ & $0 \%$ & $7 \%$ & $13 \%$ & $17 \%$ & $8 \%$ & $36 \%$ & $21 \%$ \\
\hline & Reduzido & $0 \%$ & $0 \%$ & $11 \%$ & $11 \%$ & $11 \%$ & $18 \%$ & $23 \%$ & $21 \%$ & $20 \%$ & $17 \%$ & $8 \%$ & $9 \%$ & $14 \%$ \\
\hline & N. Pagadores & 5 & 6 & 9 & 9 & 9 & 11 & 13 & 14 & 15 & 12 & 12 & 11 & 126 \\
\hline \multirow[t]{4}{*}{ Transporte Serviços } & Incremental & $0 \%$ & $67 \%$ & $80 \%$ & $67 \%$ & $86 \%$ & $71 \%$ & $63 \%$ & $75 \%$ & $50 \%$ & $63 \%$ & $63 \%$ & $67 \%$ & $67 \%$ \\
\hline & Mínimo & $100 \%$ & $33 \%$ & $0 \%$ & $17 \%$ & $0 \%$ & $29 \%$ & $38 \%$ & $25 \%$ & $50 \%$ & $25 \%$ & $13 \%$ & $22 \%$ & $24 \%$ \\
\hline & Reduzido & $0 \%$ & $0 \%$ & $20 \%$ & $17 \%$ & $14 \%$ & $0 \%$ & $0 \%$ & $0 \%$ & $0 \%$ & $13 \%$ & $25 \%$ & $11 \%$ & $9 \%$ \\
\hline & N. Pagadores & 1 & 3 & 5 & 6 & 7 & 7 & 8 & 8 & 8 & 8 & 8 & 9 & 78 \\
\hline \multirow[t]{4}{*}{ Veículos e Peças } & Incremental & $67 \%$ & $75 \%$ & $60 \%$ & $100 \%$ & $100 \%$ & $83 \%$ & $83 \%$ & $83 \%$ & $100 \%$ & $86 \%$ & $83 \%$ & $33 \%$ & $80 \%$ \\
\hline & Mínimo & $0 \%$ & $0 \%$ & $0 \%$ & $0 \%$ & $0 \%$ & $0 \%$ & $0 \%$ & $0 \%$ & $0 \%$ & $0 \%$ & $17 \%$ & $17 \%$ & $3 \%$ \\
\hline & Reduzido & $33 \%$ & $25 \%$ & $40 \%$ & $0 \%$ & $0 \%$ & $17 \%$ & $17 \%$ & $17 \%$ & $0 \%$ & $14 \%$ & $0 \%$ & $50 \%$ & $17 \%$ \\
\hline & N. Pagadores & 3 & 4 & 5 & 5 & 5 & 6 & 6 & 6 & 6 & 7 & 6 & 6 & 65 \\
\hline \multirow[t]{4}{*}{ Outros } & Incremental & $83 \%$ & $94 \%$ & $56 \%$ & $50 \%$ & $61 \%$ & $46 \%$ & $58 \%$ & $59 \%$ & $58 \%$ & $48 \%$ & $65 \%$ & $66 \%$ & $60 \%$ \\
\hline & Mínimo & $8 \%$ & $0 \%$ & $19 \%$ & $20 \%$ & $4 \%$ & $25 \%$ & $13 \%$ & $19 \%$ & $19 \%$ & $33 \%$ & $16 \%$ & $17 \%$ & $18 \%$ \\
\hline & Reduzido & $8 \%$ & $6 \%$ & $25 \%$ & $30 \%$ & $35 \%$ & $29 \%$ & $29 \%$ & $22 \%$ & $23 \%$ & $20 \%$ & $18 \%$ & $17 \%$ & $22 \%$ \\
\hline & N. Pagadores & 12 & 16 & 16 & 20 & 23 & 28 & 31 & 37 & 43 & 46 & 49 & 47 & 368 \\
\hline
\end{tabular}


$\mathrm{Na}$ Tabela 13, confirma-se os achados anteriores, em que a maioria das empresas estudadas paga payout incremental, poucos são os momentos em que isto não ocorre. Também que alguns setores distribuíram dividendos incrementais em todos os anos caso de Maquinaria Industrial de Software e Dados. Dos demais setores, apenas o de Construção foi o que teve mais de $50 \%$ de suas empresas optando pelo pagamento de payout mínimo, o mesmo foi encontrado por Vancin e Procianoy (2014). Já, quanto o pagamento de dividendos reduzidos, tem-se um baixo percentual de empresas que assim optaram por fazer, apenas os setores de Alimentos e Bebidas, Química e Outros tiveram mais de $20 \%$ das empresas classificadas neste nível de payout.

Para justificar a propensão em pagar dividendos incrementais pode-se remeter a duas suposições a serem respondidas em estudos futuros, a ocorrência da hipótese do custo de agência e o fluxo de caixa e da teoria do pássaro na mão. Na primeira haveria preferência em pagar maiores dividendos e reduzir o caixa disponível aos gestores, sejam eles acionistas controladores, ou não, para evitar uso indevido do caixa em proveito próprio. $\mathrm{Na}$ teoria do pássaro na mão, distribuem-se maiores dividendos em virtude da preferência dos investidores em recebe-los a aguardar possíveis ganhos futuros advindos do investimento de lucros retidos.

Por sua vez, para identificar se as empresas que pagaram payout incremental, mínimo ou reduzido, continuaram a fazê-lo durante os anos de análise, apresentam-se as respectivas avaliações de continuidade de pagamento de dividendos na Tabela 14, na Tabela 15 e na Tabela 16. Rememora-se que, para interpretação, combinam-se as linhas com as colunas.

Tabela 14 - Continuidade de pagamento de payout incremental

\begin{tabular}{|l|c|c|c|}
\hline \multicolumn{1}{c|}{ Payout Incremental } & Total & Distribuiu outro nível de payout & Não Distribuiu outro nível de payout \\
\hline Não paga Incremental & $32,59 \%$ & $64,03 \%$ & $35,95 \%$ \\
\hline Paga Incremental & $67,11 \%$ & $16,83 \%$ & $83,17 \%$ \\
\hline
\end{tabular}

Pelos dados da Tabela 14, do total das empresas pagadoras de dividendos da amostra, $32,59 \%$ não pagou valor incremental, dessas, 64,03\% passaram a distribuir outro nível de payout (mínimo ou reduzido) no período analisado e 35,97\% distribuíram payout incremental em algum momento. Por sua vez, das empresas pagadoras de dividendos incrementais, representando $67,11 \%$ da amostra, $83,17 \%$, assim se mantiveram por todos os anos, e $16,83 \%$ também distribuíram dividendos mínimos ou reduzidos em algum momento.

Segundo dados da Tabela 15, das empresas pagadoras de dividendos, 19,85\% optaram por distribuir dividendos mínimos, dessas, 58,13\% mantiveram esta escolha durante todo o período, e 41,87\% pagou dividendos reduzidos ou incrementais em pelo menos um ano. Por sua vez, $80,56 \%$ não pagou dividendos mínimos, das quais, $89,16 \%$ assim se manteve durante os anos analisados e apenas $10,84 \%$ distribuiu em algum momento.

Tabela 15 - Continuidade de pagamento de payout mínimo

\begin{tabular}{|c|c|c|c|}
\hline Payout Mínimo & Total & Distribuiu outro nível de payout & Não Distribuiu outro nível de payout \\
\hline Não paga o Mínimo & $80,56 \%$ & $89,16 \%$ & $10,84 \%$ \\
\hline Pagaram o Mínimo & $19,85 \%$ & $41,87 \%$ & $58,13 \%$ \\
\hline
\end{tabular}

Na Tabela 16, que versa sobre a continuidade de pagamento de payout reduzido, dos $12,73 \%$ de empresas pagadoras de payout reduzido $47,93 \%$ continuaram a fazer por todos os anos e $51,85 \%$ distribuíram valores mínimos ou incrementais em algum momento. Das empresas que não distribuíram payout reduzido, 93,15\% assim se mantiveram e $6,85 \%$ adotaram níveis de payout mínimo ou incremental. 
Tabela 16 - Continuidade de pagamento de payout reduzido

\begin{tabular}{|l|c|c|c}
\hline \multicolumn{1}{c}{ Payout Reduzido } & \multicolumn{1}{c}{ Total } & \multicolumn{1}{c}{ Distribuiu outro nível de payout } & Não Distribuiu outro nível de payout \\
\hline Não pagam Reduzido & $87,27 \%$ & $93,15 \%$ & $6,85 \%$ \\
\hline Pagam Reduzido & $12,73 \%$ & $52,07 \%$ & $47,93 \%$ \\
\hline
\end{tabular}

Em uma análise geral das tabelas 14, 15 e 16, é possível observar que há uma tendência das empresas manterem o nível de payout adotado ao longo dos anos, principalmente se mínimos ou incrementais. Esses resultados corroboram com Lintner (1956), que observou a relutância dos gestores em modificar a política de dividendos.

\section{Considerações Finais}

Este estudo teve como objetivo investigar a política de distribuição de dividendos adotada pelas empresas listadas na Bolsa de Valores de São Paulo (BM\&FBovespa) no período de 2002 a 2013. Investigando se essas empresas pagaram, ou não, dividendos; a forma que o pagaram, se Juros sobre Capital Próprio e/ou dividendos; os níveis de payout adotados, com base em seus estatutos sociais e nas normas legais que versam sobre o assunto.

Inicialmente foi observado o payout mínimo adotados pelas empresas estudadas, para tanto, foram levantados e analisados seus estatutos sociais. Foi encontrado que $89 \%$ das empresas adotam como dividendos mínimos um payout de $25 \%$ do lucro líquido ajustado (LLA), $9 \%$ payout's maiores do que $25 \%$ do LLA e apenas $2 \%$ payout abaixo de $25 \%$. Como não há determinação legal de dividendos mínimos, esses resultados levaram ao entendimento de que os gestores das empresas optam por uma política de pagamento dividendos comum ao mercado ao invés de uma política que siga as características próprias das empresas ou do setor a que pertencem, assim como percebido por Silva (2015).

Uma outra justificativa à adoção de $25 \%$ do LLA como dividendos mínimos obrigatórios pode estar no $\S 1^{\circ}$ do artigo 152 da Lei das S.A. Neste, é determinado que apenas poderá haver participação dos administradores no lucro quando os dividendos mínimos obrigatórios forem $25 \%$ ou mais do Lucro Líquido do período. Dessa forma, pode-se sugerir que na adoção da política de dividendos há um provável conflito de agência envolvendo a remuneração dos administradores.

Avaliando o pagamento de dividendos, primeiramente foi identificado que a maioria das empresas da amostra pagou dividendos, e o fez em todos os anos. Entretanto este pagamento esteve a trelado a existência do LLA, o que refuta a perspectiva de que as empresas manteriam o pagamento de dividendos para evitar insegurança dos investidores e, por conseguinte, uma redução no valor da empresa.

Também foi observado que a maior parte das empresas remunerou seus acionistas apenas com dividendos ou tendo-os em sua composição, não adotando os JSCP como poderiam para obtenção de economia tributária. Essa certa rejeição aos JSCP pode também ocorrer para evitar oneração tributária dos acionistas majoritários, que em sua grande maioria tem personalidade jurídica, este resultado direcionar a existência de um conflito de agência.

Quanto à avaliação dos payout pagos pelas empresas, em relação ao mínimo estabelecido no estatuto social, os resultados mostraram que o payout médio anual distribuído esteve acima dos $25 \%$ do LLA. Corroborando com esse achado, foi visto que mais de $60 \%$ das distribuições de dividendos estiveram acima do mínimo estatutário, ou seja, na maioria das vezes as empresas pagaram payout incremental. Concomitantemente, identificou-se que a maioria das empresas que distribuem esse payout incremental assim fizeram em todos os anos.

Dessa forma, conclui-se não apenas que existe o pagamento de payout incremental, mas, também, que é uma prática adotada pela maioria das empresas quando distribuem dividendos. 
Ou seja, mesmo que as companhias adotem comumente um payout mínimo estatutário de $25 \%$ do LLA, preferem distribuir dividendos acima desse percentual.

Nos resultados também foi visto a perseverança dos gestores quanto a política de distribuição de dividendos, como Lintner (1956) preconizou, assim os gestores em sua maioria optaram por manter a prática de pagar, ou não, dividendos, bem como a forma de distribuição e o nível de payout. Além disso, a pertença a determinado setor econômico influencia a política de distribuição de dividendos.

Por fim, para estudos futuros sugere-se a continuidade e aprofundamento de estudos que versem sobre padrões de políticas de distribuição de dividendos, ratificando os resultados. Dentre as sugestões está a investigação da composição do conselho administrativo e da composição acionária para ratificar, ou não, a ocorrência dos conflitos de agência. Além disso, acredita-se na relevância da utilização do payout calculado conforme as normas legais nos diversos estudos de dividendos.

\section{Referências}

AL-MALKAWI, RAFFERTY, PILLAI Dividend Policy: A review of theories and empirical evidence. International Bulletin of Business Administration. v. 9, p. 171-200, 2010.

ALLEN, Franklin; BERNARD; Antonio E. e WELCH, Ivo. A theory of dividends based on tax clienteles. Journal of Finance. v. 55, p. 2499-2536, 2000. doi: 10.1111/0022-1082.00298

BAKER, H. K. Dividends and dividend policy: An overview. In: BAKER, H. K.; KOLB, R. W. Dividends and Dividend Policy. Hoboken: John Wiley \& Sons, Inc,. Cap. 1, p. 3-19, 2009.

BASKIN, Jonathan B., MIRANTI. The development of corporate financial markets in britain and the united states, 1600-1914: Overcoming Asymmetric Information. The Business History Review, v. 62, p. 199-237, 1988. doi: 10.2307/3115999

BATTACHARYA, Sudipto. Imperfect information, dividend policy, and "the bird in the hand" fallacy. Bell Journal of Economics, v. 10, p. 259-270, 1979. doi: 10.2469/dig.v27.n1.3

BRASIL. Comissão de Valores Mobiliários. Deliberação n. 683, de 30 de agosto de 2012, Lex: aprova a interpretação técnica ICPC 08(R1) do Comitê de Pronunciamentos Contábeis, que trata da contabilização da proposta de pagamento de dividendos.

BRASIL, Lei 9.249, de 26 de dezembro de 1995. Lex: Altera a legislação do imposto de renda das pessoas jurídicas, bem como da contribuição social sobre o lucro líquido, e dá outras providências.

BRASIL, Lei n. 6.404, de 15 de dezembro de 1976. Lex: Dispõe sobre as Sociedades por Ações.

BRAV, Alon; JOHN R. Graham; CAMPBELL Harvey; MICHAELY, Roni. payout policy in the 21st Century. Journal of Financial Economics, v. 77, p. 483-527, 2005. doi: $10.3386 /$ w9657

BREALEY, Richard A.; MYERS, Stewart C.; ALLEN, Franklin. Princípios de Finanças Corporativas. 8. ed. São Paulo: McGraw-Hill, 2008. 
COLOMBO, J. A.; TERRA, P. R. S. Juros sobre o capital próprio, estrutura e propriedade e destruição de valor: evidências no Brasil. In: ENCONTRO NACIONAL DE ECONOMIA, 20., 2012. Porto de Galinhas. Anais...: Associação Nacional dos Centros de Pós-graduação em Economia, 2012, Disponível em: https://www.anpec.org.br/encontro/2012/inscricao/files_I/i7896d14b44c6f1324c15e31e1789490ec.pdf. Acesso em 29 Nov 2017.

DEANGELO, H., DEANGELO, L., \& STULZ, R. Dividend policy and the earned/contributed capital mix: a test of the life-cycle theory. Journal of Financial Economics, v. 81, n. 2, p. 227 254, 2006. doi: 10.1016/j.jfineco.2005.07.005

DENIS, D.; STEPANYAN, G. Factors Influencing Dividends. In: BAKER, H. K.; KOLB, R. W. Dividends and Dividends Policy. Hoboken: John Wiley \& Sons, Inc, 2009. Cap. 4, p. 5569.

ELTON, E.; GRUBER, M. Marginal Stockholders Tax rates and the clientele effect. Review of Economics and Statistics, Harvard, v. 52, p. 68-74, 1970. doi: 10.2307/1927599

EASTERBROOK, Frank H. Two agency costs explanations of dividends. American Economic Review, v. 74, p. 650-659, 1984.

FAMA, Eugene; FRENCH, Kenneth. Disappearing dividends: changing firm characteristics or lower propensity to pay? Journal of Financial Economics. v. 60 n. 1, p. 3-44, 2001. doi: 10.1016/S0304-405X(01)00038-1

FRANKFURTER, George, M; WOOD, Bob G. Jr. The evolution of corporate dividend policy. Journal of Financial Education, v. 23, p. 16-33, 1997.

GORDON, M.J. Dividends, earnings and stock prices. The Review of Economics and Statistics, Harvard, v.41, n.2, Part 1, p. 99-105, 1959.

HEINEBERG, R; PROCIANOY, J. L. Aspectos determinantes do pagamento de proventos em dinheiro das empresas com ações negociadas na Bovespa. In: XXVII EnANPAD, 2003, Atibaia. Anais... Atibaia: ANPAD, 2003. Disponível em: http://www.anpad.org.br/admin/pdf/enanpad2003-fin-1222.pdf Acessado em: 29/11/2017

JENSEN, Michael. Agency costs and free cash flow, corporate finance, and takeovers. American Economic Review, v. 76, n. 2, p. 323-329, 1986.

JENSEN, Michael; MECKLING, William. Theory of the firm: managerial behavior, agency costs and ownership structure. Journal of Financial Economics. v. 3. p. 305 - 360, 1976.

LAGIOIA, U. C. T.; MACIEL, C. V.; LIBONATI, J. J. Aspectos pagamento de juros sobre o capital próprio x distribuição de dividendos pela óptica tributária. In: Congresso Brasileiro de Contabilidade, 18., 2008, Gramado. Anais... Congresso Brasileiro de Contabilidade, 2008. CD-ROM.

LEASE, Ronald C., KOSE John; KALAY, Avner, LOEWENSTEIN, Uri; SARIG. Oded H. Dividend policy: Its impact on firm value, Harvard Business School Press, Boston, Massachusttes, 2000. 
LINTNER, John. Distribution of incomes of corporations among dividends, retained earnings, and taxes. American Economic Review. v. 46, n. 2, p. 97-113, 1956.

MILLER, M. MODIGLIANI, F. Dividend policy, growth, and the valuation of shares. Journal of business. v. 34, p. 411-33, 1961.

SILVA, M. C. C.; GALVÃO, Kécia da S.; SANTOS, J. Florencio; SOUZA, B. C. Política de dividendos: análise das empresas que compõem os índices amplo, setorial e de governança da Bm\&F Bovespa De 2010 A 2012. Revista de Finanças Aplicadas. v. 3, p.1-29, 2015.

STATACORP. Stata Statistical Software: Release 12. College Station, TX: StataCorp LP, 2011.

VANCI, D; PROCIANOY, J. L. Dividendos: a vontade de pagar, ou não, das empresas brasileiras de capital aberto. In: ENCONTRO BRASILEIRO DE FINANÇAS, 14., 2014. Anais... Recife: Sociedade Brasileira de Finanças, 2014, Disponível em: http://www.sbfin.org.br/site/Encontros/2014/artigosaceitos?action=AttachFile\&do=get\&targe t=ID4561.pdf. Acesso em: 10 Dez2014. 